\title{
Topography of Arc/Arg3.1 mRNA Expression in the Dorsal and Ventral Hippocampus Induced by Recent and Remote Spatial Memory Recall: Dissociation of CA3 and CA1 Activation
}

\author{
Pavel A. Gusev, ${ }^{1}$ Changhai Cui, ${ }^{1}$ Daniel L. Alkon, ${ }^{1}$ and Alexander N. Gubin ${ }^{2}$ \\ ${ }^{1}$ Blanchette Rockefeller Neurosciences Institute, Rockville, Maryland 20850, and ${ }^{2}$ Food and Drug Administration, Laboratory of Developmental Biology, \\ Bethesda, Maryland 20892
}

\begin{abstract}
The understanding of the mechanisms of memory retrieval and its deficits, and the detection of memory underlying neuronal plasticity, is greatly impeded by a lack of precise knowledge of the brain circuitry that underlies the functions of memory. The specific roles of anatomically distinct hippocampal subdivisions in recent and long-term memory retention and recall are essentially unknown. To address these questions, we mapped the expression of Arc/Arg 3.1 mRNA, a neuronal activity marker, in memory retention at multiple rostrocaudal levels of the dentate gyrus, CA3, CA1, subiculum, and lateral and medial entorhinal cortices after a platform search in a water-maze spatial task at $24 \mathrm{~h}$ and 1 month compared with swim and naive controls. We found that the entorhinohippocampal neuronal activity underlying the recall of recent and remote spatial memory has an anatomically distributed and time-dependent organization throughout both the dorsal and ventral hippocampus that is subdivision specific. We found a dissociation in the activity of the entorhinal cortex, CA3, and CA1 over a period of memory consolidation. Although CA3, the dorsal hippocampus, and the entorhinal cortex demonstrated the most persistent learning-specific signal during both recent and long-term memory recall, CA1 and the ventral hippocampus displayed the most dramatic signal decline. We determined the coordinates of activity clusters in the hippocampal subdivisions during the platform search and their dynamics over time. Our mapping data suggest that although the level of corticohippocampal interaction is similar during the retrieval of recent and remote spatial memories, the mnemonic function of the hippocampus may have changed, and the activity underlying remote spatial memory could be anatomically segregated within hippocampal subdivisions in small segments.
\end{abstract}

Key words: memory; stress; consolidation; hippocampus; water maze; immediate-early gene; corticosterone

\section{Introduction}

Retrieval memory deficits are frequently observed with aging and may also serve as early predictors of Alzheimer's disease (Tuokko et al., 1991; Gallagher and Rapp, 1997; Backman et al., 1999). Water-maze spatial memory in rodents has been used extensively as an animal model for human spatial memory (Morris, 1984), but the mechanisms of retrieval still remain elusive (de Hoz et al., 2004). Although the dorsal hippocampus (dHC) appears to be specifically involved in the fast acquisition of water-maze spatial memory, it may be encoded and subsequently retrieved by networks extending into the ventral $\mathrm{HC}(\mathrm{vHC})$ that make it critical for successful memory recall (Moser et al., 1995; Moser and

\footnotetext{
Received March 2, 2005; revised Aug. 18, 2005; accepted Aug. 18, 2005.

We thank Thomas Nelson for Northern blotting and help with autoradiogram analysis, Li Bai for excellent technical assistance, Alessia Pascale for the introduction to cryostat sectioning and in situ hybridization techniques, Madelon Cook for manuscript assistance, Brad Zoltick for computer support, and Michele P. Kelly and Gary Brooker for helpful advice.

Correspondence should be addressed to Pavel A. Gusev, Blanchette Rockefeller Neurosciences Institute, 9601 Medical Center Drive, Academic and Research Building, Room 316, Rockville, MD 20850-3332. E-mail: gusevpa@brni-jhu.org.

DOI:10.1523/JNEUROSCI.0832-05.2005

Copyright $\odot 2005$ Society for Neuroscience $\quad$ 0270-6474/05/259384-14\$15.00/0
}

Moser, 1998a; Bannerman et al., 1999, 2004; Riedel et al., 1999; Steffenach et al., 2002; de Hoz et al., 2004; Pothuizen et al., 2004; Zhang et al., 2004). There is substantial uncertainty, however, about the precise topography of the entorhinohippocampal circuitry that underlies spatial memory over an extended retention period (Squire, 1992; Nadel and Moscovitch, 1997; Milner et al., 1998; Sutherland et al., 2001). The specific roles of the hippocampal anatomical subdivisions in memory storage and recall, and their time frames, are essentially unknown.

To clarify the topography and dynamics of the entorhinohippocampal circuitries that specifically underlie the retrieval of recently acquired and consolidated memories over a period of 1 month, we applied a noninvasive technique based on the imaging of Arc/Arg3.1 mRNA at the multiple rostrocaudal levels of the HC. Arc mRNA is a sensitive marker of neuronal activity and an effector immediate-early gene that is critically involved in spatial memory formation (Link et al., 1995; Lyford et al., 1995; Guzowski et al., 1999, 2000, 2001, 2002). Arc mRNA reflects regional specificity for space encoding that has been demonstrated by neuronal ensemble recordings (Lee et al., 2004; Leutgeb et al., 2004; Vazdarjanova and Guzowski, 2004).

We hypothesized that the search for an escape platform dur- 
A

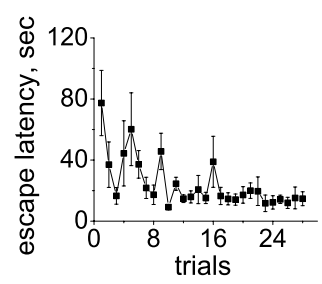

D

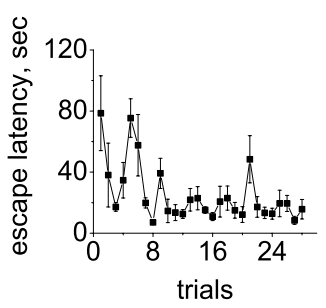

B

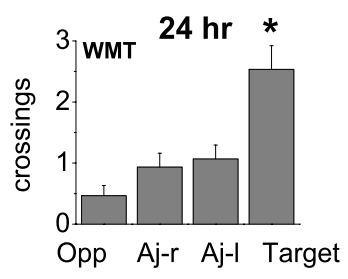

E

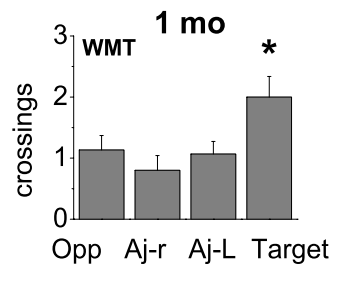

G
H

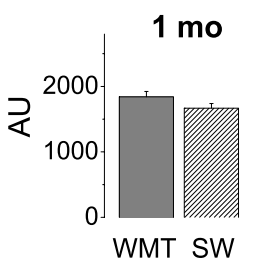

I

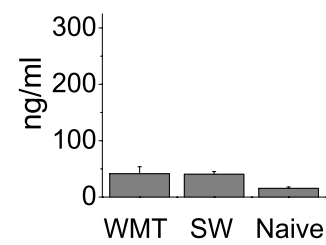

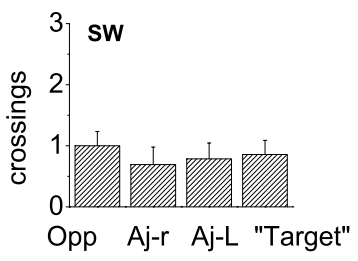

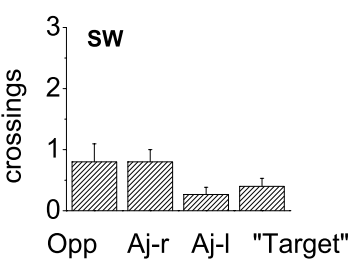

$\mathbf{F}$
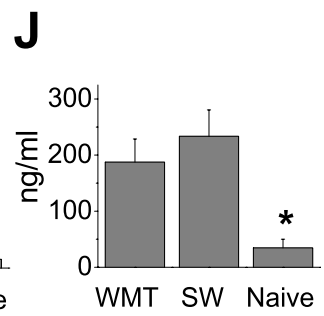

Figure 1. Acquisition and long-term retention of spatial memory in the water-maze task. $A, D$, Escape latency dynamics during water-maze training. $\boldsymbol{B}, \boldsymbol{E}$, Probe tests performed $24 \mathrm{~h}(\boldsymbol{B})$ and 1 month $(\boldsymbol{E})$ after $7 \mathrm{~d}$ of water-maze training. Error bars indicate SEM of the number of crossings over the target location and nontarget quadrant centers. Note the spatial bias in the swim tracks of WMT rats. The target quadrant contained an escape platform during training trials. $\boldsymbol{C}, \boldsymbol{F}$, There was no spatial bias in the swimming pathways of SW yoked controls at both $24 \mathrm{~h}$ and 1 month after the last session. $\mathbf{G}, \boldsymbol{H}$, There was no difference in the distance swum by WMT and SW rats at $24 \mathrm{~h}(\boldsymbol{G})$ and 1 month $(\boldsymbol{H})$ after the last training session. $\boldsymbol{I}, \boldsymbol{J}$, There was no difference in corticosterone levels after training room context exposure $(\boldsymbol{I})$ and probe tests $(\boldsymbol{J}) 24 \mathrm{~h}$ after the last training session. Error bars indicate SEM; * $p<0.05$; one-way ANOVA with Fisher's post hoc test. Opp, Opposite to target quadrant; Aj-r, adjacent right quadrant; $A j-I$, adjacent left quadrant; $A U$, arbitrary units.

ing the probe tests performed at $24 \mathrm{~h}$ and 1 month in memory retention would activate the brain regions that specifically underlie navigation and putative memory storage sites that could be identified by Arc mRNA expression. We propose that a comparative analysis of circuit topography activated by memory recall in normal and aging animals will be useful for understanding the mechanisms of retrieval deficits and that detailed knowledge of brain activity distribution will make the detection of memory underlying neuronal plasticity a more feasible task. Enduring intrinsic and synaptic correlates of recent and long-term memories were detected recently on the basis of the precise knowledge of brain subregions that are critical for memory function (Schreurs et al., 1997, 1998; Gusev and Alkon, 2001).

We found that the entorhinohippocampal neuronal activity that underlies the recall of recent and remote spatial memories has an anatomically distributed and time-dependent organization throughout the HC. Although CA3, the dorsal HC, and the entorhinal cortex demonstrated a learning-specific signal during both recent and long-term memory recall, the specific activity of $\mathrm{CA} 1$ and the ventral HC displayed a dramatic decline. We observed that clusters of activity in the HC subdivisions and cluster coordinates changed over time.

\section{Materials and Methods}

Training procedure. The subjects were 54 8-week-old male Wistar rats (Charles River Laboratories, Wilmington, MA). Rats were caged individually, given ad libitum access to food and water, and maintained on a $12 \mathrm{~h}$ light/ dark cycle. Animal care and maintenance were in accordance with National Institutes of Health guidelines. Rats were trained on a water-maze task in a swimming pool ( $1.5 \mathrm{~m}$ in diameter and $0.6 \mathrm{~m}$ high) that was filled with milky water $\left(24 \pm 1^{\circ} \mathrm{C}\right)$ and located in a well lit $(3 \times 5 \mathrm{~m})$ room with distinct extra-maze cues. Our training protocol was designed to force rats to use a spatial navigation strategy (Morris, 1984; Eichenbaum et al., 1990; Micheau et al., 2004). A transparent, square platform $(12.5 \times 12.5$ $\mathrm{cm}$ ) was hidden in a constant location (center of the quadrant) within the pool; its top surface was submerged $1.5 \mathrm{~cm}$ below the water level. On day 0 , rats were subjected to $2.5 \mathrm{~min}$ of swimming in the pool in the absence of the platform, for adaptation to the environment. On the first day, the rats were guided to the platform if they did not find it in $2 \mathrm{~min}$. For the next $7 \mathrm{~d}$, rats were trained to locate the hidden island in four trials per day. The rats were brought into the training room in a home cage one at a time. Each rat was held in an experimenter's hands for $1 \mathrm{~min}$, and then a mark was applied to its head with a wide-tip black marker so that the rat's swimming could be tracked by a Poly-Track video system (San Diego Instruments, San Diego, CA). Before the rat was introduced into the tank and the training trials were started, two 1 min walks were taken around the tank with the rat held in an experimenter's hands, with a $10 \mathrm{~s}$ stop at the border of each quadrant. The rat was introduced into the tank facing the wall of the tank at the middle of the quadrant opposite, adjacent left and right to the target quadrant. The rats were then allowed to stay on the platform for $40 \mathrm{~s}$. After each trial, the experimenter walked away from the pool and started the next trial with a $10 \mathrm{~s}$ delay from a different quadrant. The order of the starting positions was pseudorandomized and varied every day. After four trials were completed, the rat was introduced into a cage filled with clear water for 5-10 s, and then it was placed in a cardboard box filled with wood chips for $20 \mathrm{~s}$ to let it shake off the water. The rat was then toweled dry before being returned to the home cage. For all animals, there was only one target quadrant that was always in the same location. Acquisition of spatial memory was assessed on the basis of escape latencies. Two of five rats from the 1 month group were given one extra training session.

To control for nonmnemonic and mnemonic processes not specifically related to our navigational task, we used animal triads that included one swimming (SW) and one naive control animals for each water mazetrained (WMT) rat. To equalize locomotor activity and stress responses, rats from the SW yoked control group had one trial of swimming each day for the same amount of time that was required to find the platform for the corresponding WMT rat. Swimming controls spent $3 \mathrm{~min}$ in the cardboard box to equalize the time that WMT rats spent on the platform (four times for $40 \mathrm{~s}$ each).

Probe tests for brain activity mapping. During the probe tests, the WMT and SW yoked animals were treated according to the protocol followed during the training sessions, except that both groups spent $20 \mathrm{~s}$ in the cardboard box after the tests and before being returned to the home cage and housing room. After their release, the rats faced the wall in the middle of the quadrant opposite the target quadrant location and swam for $60 \mathrm{~s}$ 
Table 1. Multiple probe tests did not cause extinction of searching behavior in the water maze

\begin{tabular}{|c|c|c|c|c|c|c|}
\hline Parameter & First probe & Second probe & Third probe & Average & Last training session & $p$ value \\
\hline \multicolumn{7}{|l|}{ Recent memory } \\
\hline First target hit latency ${ }^{a}$ & $12.5 \pm 2.62$ & $14 \pm 3.97$ & $23 \pm 9.19$ & $16.7 \pm 3.57$ & \multirow[t]{4}{*}{$14.1 \pm 2.2$} & 0.73 \\
\hline Number of target area hits & $2.6 \pm 0.4$ & $3.4 \pm 0.93$ & $1.6 \pm 0.4$ & $2.5 \pm 0.39$ & & 0.16 \\
\hline Dwell time in target quadrant ${ }^{a}$ & $17.3 \pm 2.48$ & $21.4 \pm 1.33$ & $15 \pm 3.5$ & $17.9 \pm 1.57$ & & 0.2 \\
\hline Distance fraction swum in target quadrant & $1.22 \pm 0.24$ & $1.68 \pm 0.17$ & $1.15 \pm 0.32$ & $1.3 \pm 0.15$ & & 0.14 \\
\hline \multicolumn{7}{|l|}{ Remote memory } \\
\hline First target hit latency ${ }^{a}$ & $33.0 \pm 9.0$ & $15 \pm 4.64$ & $10.1 \pm 0.3$ & $19.8 \pm 4.35$ & \multirow[t]{4}{*}{$15.8 \pm 3.0$} & 0.23 \\
\hline Number of target area hits & $1.8 \pm 0.49$ & $2.0 \pm 0.71$ & $2.4 \pm 0.6$ & $2.07 \pm 0.33$ & & 0.77 \\
\hline Dwell time in target quadrant ${ }^{a}$ & $17.6 \pm 0.55$ & $21.9 \pm 0.78$ & $24.1 \pm 2.8$ & $21.4 \pm 1.22$ & & 0.055 \\
\hline Distance fraction swum in target quadrant & $1.31 \pm 0.04$ & $1.8 \pm 0.08$ & $1.95 \pm 0.34$ & $1.7 \pm 0.14$ & & 0.14 \\
\hline
\end{tabular}

Data are presented as SEM. The Kruskal-Wallis test was applied instead of ANOVA because of a slight difference in the number of data points across the consecutive water-maze probe tests and occasional differences in variance. The averag was calculated on the basis of three probe tests. Because animals were not specifically trained to wait for platform availability, dwell times that reflect a procedural aspect of the task (Micheau et al., 2004 ) in the target quadrant were short in some probe tests.

${ }^{a}$ Time in seconds.

Table 2. Learning-specific Arc mRNA expression at the level of the entire, dorsal, and ventral hippocampi in the anatomical subdivisions after navigation on the basis of recent and remote spatial memories of water maze

\begin{tabular}{|c|c|c|c|c|c|c|}
\hline \multirow[b]{2}{*}{ Subdivision } & \multicolumn{3}{|c|}{ Recent memory } & \multicolumn{3}{|c|}{ Remote memory } \\
\hline & $\mathrm{df}=n-3$ & ANOVA, F statistic & Fisher's post hoc test; $p$ value & $\mathrm{df}=n-3$ & ANOVA, F statistic & Fisher's post hoc test, $p$ value \\
\hline CA1 & 630 & 972.6 & $<0.0001$ & 783 & 1933.8 & 0.35 \\
\hline CA3 & 495 & 910.6 & $<0.0001$ & 684 & 1639.7 & $<0.0001$ \\
\hline DGdb & 507 & 409.4 & $<0.0001$ & 624 & 768 & $<0.0002$ \\
\hline Subiculum & 495 & 920.7 & $<0.0001$ & 615 & 1651.3 & $<0.0001$ \\
\hline $\mathrm{dCA} 1$ & 474 & 979.7 & $<0.0001$ & 633 & 1587.1 & 0.5 \\
\hline vCA1 & 153 & 147.9 & $<0.0001$ & 147 & 347 & 0.35 \\
\hline $\mathrm{dCA} 3$ & 435 & 1108.2 & $<0.0001$ & 582 & 1449 & $<0.0001$ \\
\hline$d-v C A 3$ & 57 & 24.7 & $<0.05$ & 99 & 232 & $<0.005$ \\
\hline $\mathrm{dDGdb}$ & 411 & 422.8 & $<0.0001$ & 567 & 761.4 & $<0.004$ \\
\hline vDGdb & 93 & 48.2 & $<0.0001$ & 54 & 38.4 & $<0.003$ \\
\hline dSub & 249 & 590.3 & $<0.0001$ & 411 & 1076.5 & $<0.0004$ \\
\hline vSub & 243 & 415.4 & $<0.0001$ & 201 & 569.9 & $<0.004$ \\
\hline
\end{tabular}

The normalized levels of Arc mRNA were compared in WMT, SW, and naive controls by one-way ANOVAs followed by Fisher's post hoc tests at $p<0.05$. $n$, Total number of data points for WMT, SW, and naive controls; df, degrees of freedom; $\mathrm{db}$, dorsal blade; $d$, dorsal; $v$, ventral; Sub, subiculum. $p$ values represent significance of WMT group difference from the $S W$ control. Differences between WMT and naive and between $S W$ and naive were always highly significant ( $p<0.0001$ ) and are not represented.

in the pool with the platform removed. Navigation skills were evaluated on the basis of the number of "target area" $(12.5 \times 12.5 \mathrm{~cm})$ crossings and latency to the first target crossing. Dwell time and distance swum in the pool quadrants were also measured. To ensure repeated activation of memory underlying the brain regions, Arc mRNA induction in a sufficient amount, and its visualization, three consecutive probe tests with $10 \mathrm{~s}$ intervals were performed $24 \mathrm{~h}$ or 1 month after the last training session. The entire test procedure took $\sim 8 \mathrm{~min}$, and it was conducted on WMT and SW rats from each triad with a $10 \mathrm{~min}$ interval. Animals were killed $30 \mathrm{~min}$ after the end of the last probe test, and the entire brains were quickly removed from the skull and placed on dry ice powder within 3 $\mathrm{min}$. Naive controls were killed last in a triad, $15 \mathrm{~min}$ after the swimming controls.

Corticosterone measurement. Stress levels caused by behavioral procedures were measured by the concentration of stress hormone in the blood separately from the mapping set of triads. These triads were trained in a slightly larger tank (diameter, $180 \mathrm{~cm}$ ). Recent memory tests and control swimming procedures were analogous to those used in the mapping experiments. The effect of the context in the water-maze training room on the stress hormone level was estimated $24 \mathrm{~h}$ after the last training session. WMT and SW rats were brought into the room, and their heads were marked. Animals were held in an experimenter's hands during the two $1 \mathrm{~min}$ walks around the pool. Afterward, they were immediately placed in home cages and returned to housing room, without starting a swimming session. Animals were taken from their home cages and killed in a procedure room cages $20 \mathrm{~min}$ after the context-only exposures and probe tests. WMT, SW, and naive rats from each triad were killed within an $80 \mathrm{~min}$ time span to ensure the same phase of the circadian rhythm for the entire triad (i.e., between 9:30 A.M. and 3:00 P.M.). Trunk blood was collected into $1.5 \mathrm{ml}$ tubes on ice containing $5 \mu \mathrm{l}$ of $0.13 \mathrm{M}$ EDTA. Sam- ples were centrifuged immediately at $4^{\circ} \mathrm{C}$ at $14,000 \mathrm{rpm}$ for $5 \mathrm{~min}$. Plasma aliquots were stored at $-80^{\circ} \mathrm{C}$. The corticosterone concentration was determined by an enzyme immunoassay kit with a 96 -well microtiter coated with polyclonal antibody raised against corticosterone following the manufacturer's instructions (Immunodiagnostic Systems, Fountain Hills, AZ). The absorbance levels were measured with a Model 550 microplate reader at $450 \mathrm{~nm}$ (reference at $655 \mathrm{~nm}$ ) (Bio-Rad, Hercules, CA).

Brain sectioning. Coronal $20-\mu \mathrm{m}$-thick cryostat sections were collected in a rostrocaudal direction across the entire brain. To be able to measure and assign coordinates to the brain sections during the forebrain sectioning and then to create anatomical maps of neuronal activity, we used the interaural system of coordinates. To obtain these coordinates, we needed to adjust the distance measured between the rostral pole of a frozen brain and the rearmost edge of the neocortex by adding $0.6 \mathrm{~mm}$. Because of small variations in brain size from animal to animal, we also compared the anatomy of sections with the rat brain atlas and made necessary adjustments before assigning coordinates (Paxinos and Watson, 1998). During the sectioning with a cryostat Leica CM 1900 (Leica, Nussloch, Germany), the coordinates were calculated on the basis of the number of $20 \mu \mathrm{m}$ sections and were measured with a compass and a ruler. The association was good among the measured, calculated and anatomical coordinates during the entire sectioning. Brain sections on the same slide were separated by no less than $60 \mu \mathrm{m}$ to avoid measuring the Arc mRNA signal in the same neurons twice. During the sectioning, each section was placed on the next silanated glass slide (K-D Medical, Columbia, MD) of a group of four slides. Three coronal sections were mounted per slide. A protocol number of a behavioral group and an estimated interaural coordinate for the last mounted section on the fourth slide were written on each of four slides so that the coordinate of each section could be calculated as precisely as possible. During the cryostat sectioning, the slides 

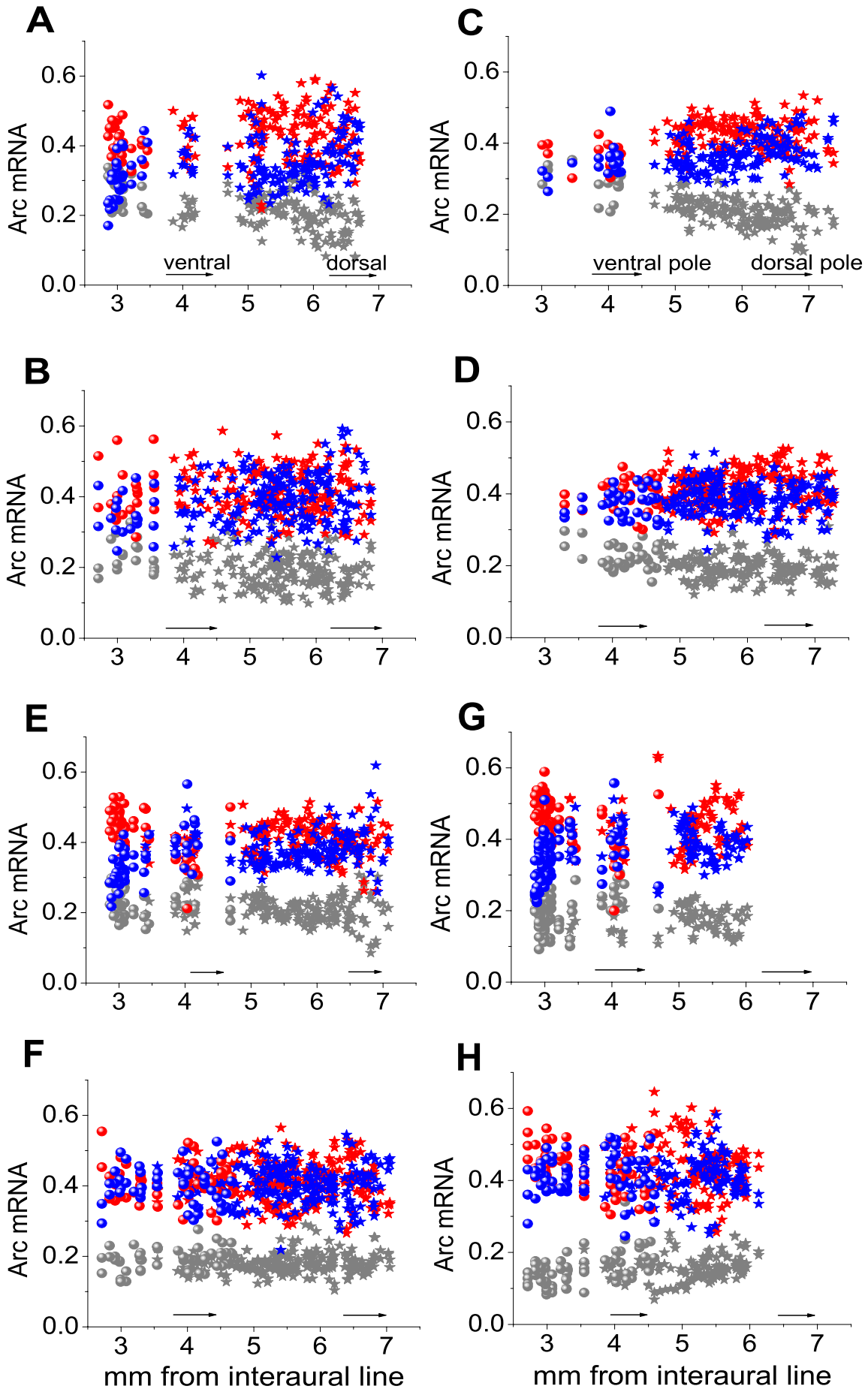

Figure 2. Distribution of Arc mRNA upregulation across the rostrocaudal axis of the hippocampus after activation of recent and long-term spatial memories. Red stars and circles indicate data for $\mathrm{dHC}$ and vHC of the WMT group. Blue and light-gray symbols indicate swimming and naive controls, respectively. Neurons with enhanced Arc mRNA expression were located at multiple rostrocaudal levels in $D G(\boldsymbol{A}, \boldsymbol{B}), C A 3(\boldsymbol{C}, \boldsymbol{D}), C \mathrm{C} 1(\boldsymbol{E})$, and subiculum $(\boldsymbol{G}, \boldsymbol{H}) 30$ min after the set of three 1 min probes of recent $(\boldsymbol{A}$, $\boldsymbol{C}, \boldsymbol{E}, \boldsymbol{G})$ and remote $(\boldsymbol{B}, \boldsymbol{D}, \boldsymbol{H})$ memories. There was no distributed learning-specific signal in $C A 1$ after long-term memory recall $(\boldsymbol{F})$. For detailed statistical analyses, see Figures 6 and 7 and supplemental Tables 1-4 (available at www.jneurosci.org as supplemental material). Data points are individual mean values of the normalized Arc mRNA levels obtained for an anatomical match in every triad. Arrows indicate direction toward the hippocampal poles. mm, Millimeter.

were kept at room temperature in a slide container. After the sectioning was complete, tissue sections were stored at $-80^{\circ} \mathrm{C}$ until use.

Reverse transcription-PCR and Arc probegeneration. Total rat RNA was purchased from Ambion (Austin, TX). Reverse transcription (RT) was performed with the oligo-dT primer and Superscript Reverse Transcrip- tase at $42^{\circ} \mathrm{C}$ for $50 \mathrm{~min}$, as suggested by the manufacturer (Invitrogen, Carlsbad, CA). We used 1 $\mu \mathrm{l}$ of RT reaction in $50 \mu \mathrm{l}$ of PCR amplification with the appropriate primers as follows: initial denaturation at $95^{\circ} \mathrm{C}$ for $2 \mathrm{~min}$; denaturing at $94^{\circ} \mathrm{C}$ for $30 \mathrm{~s}$; annealing at $62^{\circ} \mathrm{C}$ for $30 \mathrm{~s}$; and extension at $72^{\circ} \mathrm{C}$ for $3 \mathrm{~min}$ for 36 cycles. For Arc amplification, 5' -ACGGGCGACTCACAGCGCTGGA-3' and 5'-GGGTCTCCTGGGACTGGACTTGACCA-3' primers were used (expected product size, $2.1 \mathrm{~kb}$ ). The PCR product was analyzed in a $1.2 \%$ agarose gel stained with ethidium bromide (Invitrogen). The PCR product was subcloned into a pCR4-TOPO vector (Invitrogen), and the positive Arc clone was confirmed by restriction digestion and sequencing. Purified plasmid DNA was linearized with either PmeI or NotI (New England Biolabs, Beverly, MA). Both linearized DNA templates were used to generate sense and antisense RNA probes labeled with ${ }^{35} \mathrm{~S}(\alpha$ ${ }^{35}$ S-UTP; PerkinElmer, Boston, MA; Amersham Biosciences, Piscataway, NJ) with the MAXIscript kit (Ambion) according to the manufacturer's instructions. The yield and integrity of the riboprobe were verified by gel electrophoresis.

In situ hybridization histochemistry. Experiments were performed with the brain sections taken at the same brain level from the WMT, SW, and naive control animals in parallel. An exact anatomical match of the sections was performed on autoradiograms. The sections were fixed in a buffered (1 m PBS) $4 \%$ formaldehyde solution freshly prepared from paraformaldehyde for $5 \mathrm{~min}$ and rinsed in PBS two times for 5 $\mathrm{min}$. Then slices were placed in $0.25 \%$ acetic anhydride in $0.1 \mathrm{~m}$ triethanolamine for $10 \mathrm{~min}$, rinsed for $5 \mathrm{~min}$ in $2 \times$ SSC $(1 \times$ SSC $=0.15 \mathrm{M}$ $\mathrm{NaCl} / 0.015 \mathrm{~m}$ sodium citrate), and dehydrated by being passed through graded dilutions of ethanol in distilled water $(\mathrm{v} / \mathrm{v})(70,80,95$, and $100 \%)$ for $1 \mathrm{~min}$. The sections were passed through chloroform $\left(\mathrm{CHCl}_{3}\right)$ for $5 \mathrm{~min}, 100 \%$ ethanol for $1 \mathrm{~min}$, and $95 \%$ ethanol for $1 \mathrm{~min}$, and air dried for $30 \mathrm{~min}$. The Arc riboprobe $\left(1 \times 10^{6}\right.$ cpm in $50 \mu \mathrm{l}$ ) was applied to each slide holding three sections and hybridized at $55^{\circ} \mathrm{C}$ for $24 \mathrm{~h}$ in a mixture containing $20 \mathrm{~mm}$ Tris- $\mathrm{HCl}, \mathrm{pH} 7.4,1 \mathrm{~mm}$ EDTA, $300 \mathrm{~mm} \mathrm{NaCl}, 50 \%$ formamide, 10\% dextran sulfate, $1 \times$ Denhardt's solution, $4 \mu \mathrm{g} / \mathrm{ml}$ salmon sperm DNA, $10 \mu \mathrm{g} / \mathrm{ml}$ yeast total RNA, 10 $\mu \mathrm{g} / \mathrm{ml}$ yeast tRNA (Invitrogen), $100 \mathrm{~mm}$ dithiothreitol (ICN Biomedicals, Irvine, CA), 0.1\% SDS, and $0.1 \%$ NTS. Compounds were purchased from Sigma-Aldrich (St. Louis, MO) unless stated otherwise. Slices hybridized with the sense riboprobe were used as negative controls. Glass coverslips were placed on hybridizing sections. After highstringency posthybridization washes and RNase treatment, the brain sections were dehydrated in graded ethanol and then subjected to autoradiography with BioMax MR film (Eastman Kodak, Rochester, NY) together with ${ }^{14} \mathrm{C}$ microscales purchased from Amersham Biosciences (catalog \#RPA 504 and RPA 511).

Arc mRNA signal analysis. Autoradiograms were placed on a Northern Light C-60 illuminator (Imagining Research, St. Catharines, Ontario, Canada) and 12-bit images were acquired with a Hamamatsu (Tokyo, Japan) ORCA-ER digital camera and the AxioVision-3.1 program (Zeiss, Oberkochen, Germany). For each triad, 
A

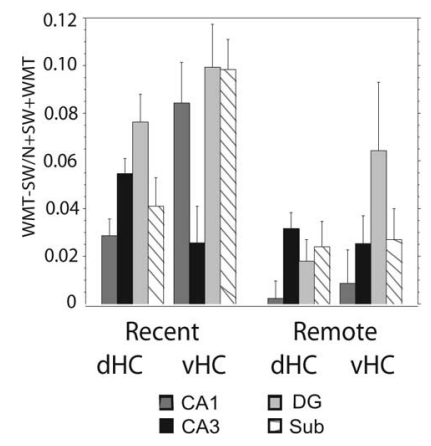

B

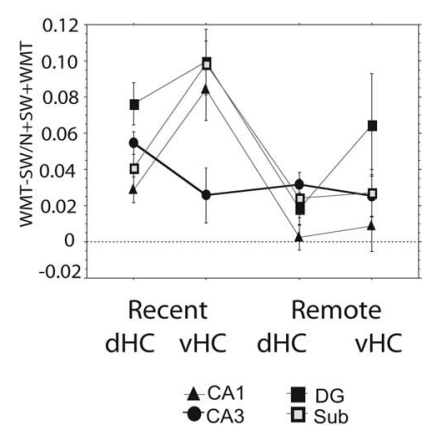

Figure 3. Factors affecting the magnitude of navigation task-specific Arc mRNA expression in the hippocampus: anatomical subdivision, its dorsal or ventral location, and a time delay since memory acquisition. $A$, Learning-specific Arc mRNA expression in hippocampal anatomical regions after recent and remote water-maze memory tests. $\boldsymbol{B}$, An interaction plot illustrates time-dependent and subdivision-specific changes in Arc mRNA expression that were most distinct in CA3 compared with DG, CA1, and subiculum. Error bars indicate SEM of WMT and SW Arc mRNA differences. Sub, Subiculum; SW/N, SW/naive.

autoradiograms of brain sections treated in the same in situ hybridization experiment and originated from WMT, SW, and naive controls were anatomically matched. Quantification of Arc mRNA signals was performed with the ImageGauge-3.36 software (Fuji Film, Tokyo, Japan) over the entire regions of the CA1, CA3, subiculum, entorhinal cortex, and dorsal blade of the dentate gyrus (DG) according to rat brain atlases (Paxinos and Watson, 1998; Swanson, 2004). Measured mean gray levels were converted into nanocuries per gram of tissue equivalents with ${ }^{14} \mathrm{C}$ microscales (Miller, 1991). Polynomial functions of three to five orders were used to create calibration curves in Origin 6.1 software (Origin Lab Corporation, Northampton, MA). The dorsal and ventral regions of the DG, CA1, and subiculum were analyzed separately (for coordinates, see Fig. 2). The ventral and dorsal CA3 areas on the same section were analyzed together and indicated as "dorsoventral CA3." These CA3 data were included in the ventral HC sample. The Arc mRNA signal in each anatomically matched experimental and control section (treated in the same in situ hybridization experiment) was normalized to a sum of signal intensities measured in WMT, SW, and naive sections of this individual match. These individual normalized values obtained in the multiple in situ hybridization experiments at different rostrocaudal levels of each triad were pooled for final statistical analyses. The magnitudes of learning-specific signals were calculated as a difference between normalized Arc mRNA levels in WMT and SW sections in each individual anatomical match of each triad. In a subset of autoradiograms, the hippocampal subdivisions were selected by the experimenter, who was not aware of the behavioral conditions. This blind analysis yielded results that were similar to the outcome of a non-blind analysis of the same autoradiograms. To avoid further bias, data were statistically analyzed only after all the samples were complete. Thus, the Arc mRNA signal measurements were taken without benefit of advance knowledge of the effects that emerged.

Statistical analyses. The normality of data distributions and variance equality were verified by the Kolmogorov-Smirnov test and $F$ test, respectively. The acquisition of spatial memory in the Morris water-maze task was evaluated by repeated measures ANOVA. Performance on recent and long-term spatial memory tasks was assessed by one-way ANOVA followed by a Fisher's post hoc test and a Kruskal-Wallis test, where appropriate (Statview; SAS Institute, Cary, NC). The presence of a learning-specific signal in the individual subregions was assessed by multiple region-by-region univariate ANOVAs followed by a Fisher's post hoc test on pooled data. The main and combined effects of the memory retention period and the anatomical $\mathrm{HC}$ subdivision and its rostrocaudal position in the brain on learning-specific Arc mRNA expression were evaluated by three-way ANOVAs on pooled data. The effects of time elapsed since memory acquisition on behavior and on Arc mRNA expression were assessed by Student's $t$ tests.

\section{Results}

\section{Rats recall a hidden platform position without decline, 1 month after training}

It was important to develop a behavioral training protocol under which rats remembered a platform location for 1 month without decline. The recent and remote memory groups included five animal triads each. Groups trained for the study of recent and remote spatial memories displayed a similar time course of watermaze learning with a characteristic significant improvement in the escape latency over the first trials ( 5 and 5 , respectively) (Fig. $1 A, D$ ). A 2 (groups) $\times 7$ (days of trials) ANOVA with repeated measures on the second factor revealed a significant main effects of days $\left(F_{(6,63)}=8.104 ; p<0.0001\right)$ and trials $\left(F_{(3,36)}=16.94 ; p<0.0001\right)$ without a significant effect of groups $\left(F_{(1,18)}=0.03 ; p>0.8\right)$ and without a significant interaction among all factors $\left(F_{(18,162)}=0.45 ; p>0.9\right)$. Rats reached an asymptotic performance simultaneously, and there was no difference in the acquisition rate of the water-maze task as measured by the escape latencies.

Probe tests indicated a clear spatial preference for the target location both $24 \mathrm{~h}$ and 1 month after the last training session $(n=$ 15 and 15 , respectively; $n=$ number of tests) (Fig. $1 B, E$ ). There was a higher number of hits for target quadrant centers (hidden platform location) compared with non-target quadrants recorded for each trained animal during three consecutive probe tests $\left(F_{(3,56)}=11.3, p<0.0001 ; p<0.0001, p<0.0001, p<\right.$ 0.0003 , Fisher's post hoc test; $F_{(3,56)}=4.58, p<0.01 ; p<0.013$, $p<0.001, p<0.009$ ) and by dwell time and distance swum in the target and control quadrants (data not shown). However, swimming-only, yoked control rats for both the $24 \mathrm{~h}$ and $1 \mathrm{month}$ groups did not demonstrate spatial bias as measured by numbers of hits for "target" quadrant centers compared with non-target quadrants recorded for each animal during three consecutive "probe" tests $\left(F_{(3,48)}=1.72, p>0.17 ; F_{(3,51)}=0.26, p>0.8\right)(n=$ 15 and 15, respectively) (Fig. 1C,F) and in the dwell time and swim track lengths (data not shown).

There was no memory decline over a 1 month retention period as measured by a number of parameters. First, there was no difference in the quadrant analyses of target or non-target quadrant center hits during a 1 month delay probe test compared with a $24 \mathrm{~h}$ delay test. This was indicated by the absence of any statistically significant interaction between "target and nontarget hits" and "memory retention" factors $\left(F_{(3,36)}=1.62 ; p>0.19\right)$ (Fig. 1, compare $B, E$ ); the main effect of memory retention on the performance of the rats was not significant $\left(F_{(1,18)}=0.009 ; p>0.9\right)$. The performance of the rats was not different as measured by the number of platform location crossings ( $p>0.3$; Student's $t$ test) [Table 1 (values are compared across all three probe tests; see Average column)], by dwell time and distance swum in the target quadrant $(p>0.08 ; p>0.07)$, and by target crossing latency during the three consecutive probe tests $24 \mathrm{~h}$ and 1 month after the last training session $(p>0.5)$. There was no difference in the total length of swim pathways by WMT and SW control rats in the retention groups $(p>0.4 ; p>0.1)(n=15$ and 15 , respectively) (Fig. 1G,H). A nonspecific difference was that both WMT and SW control rats from the 1 month retention group swam a slightly shorter distance when compared with the 24 h group $(p<0.0001 ; p<0.01)$.

We did not observe signs of searching behavior extinction during consecutive probe tests as assessed by the Kruskal-Wallis test for latency of the first target location hit, target hit numbers, dwell time, and distance swum in the target quadrant measured 


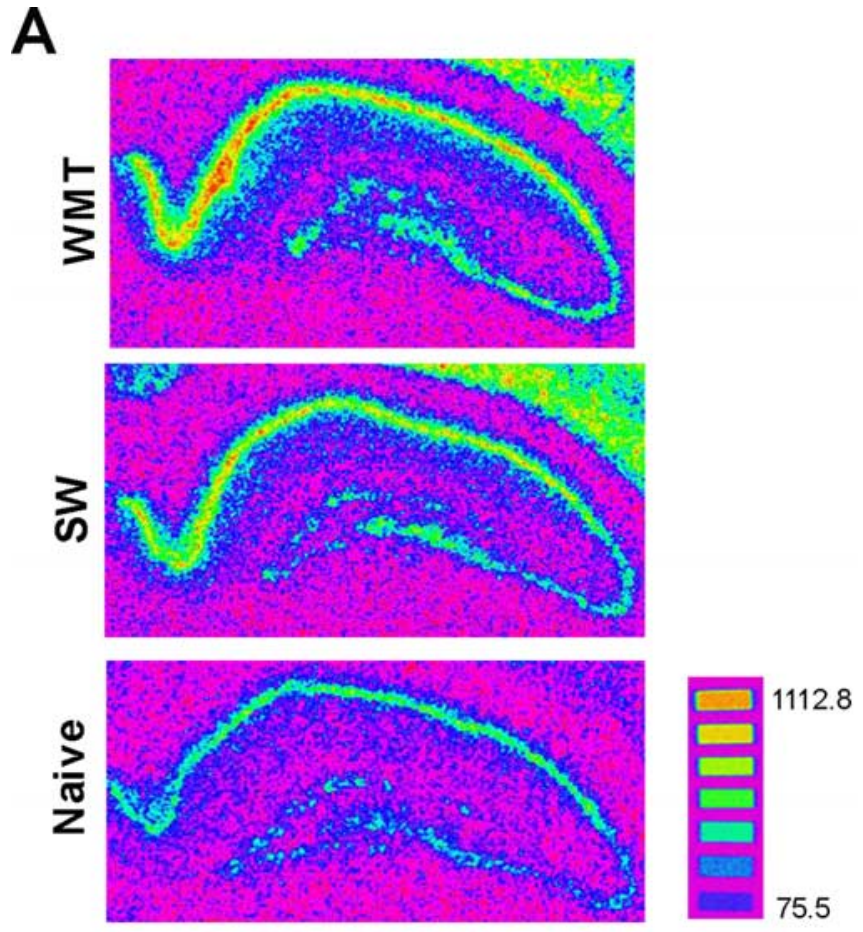

B
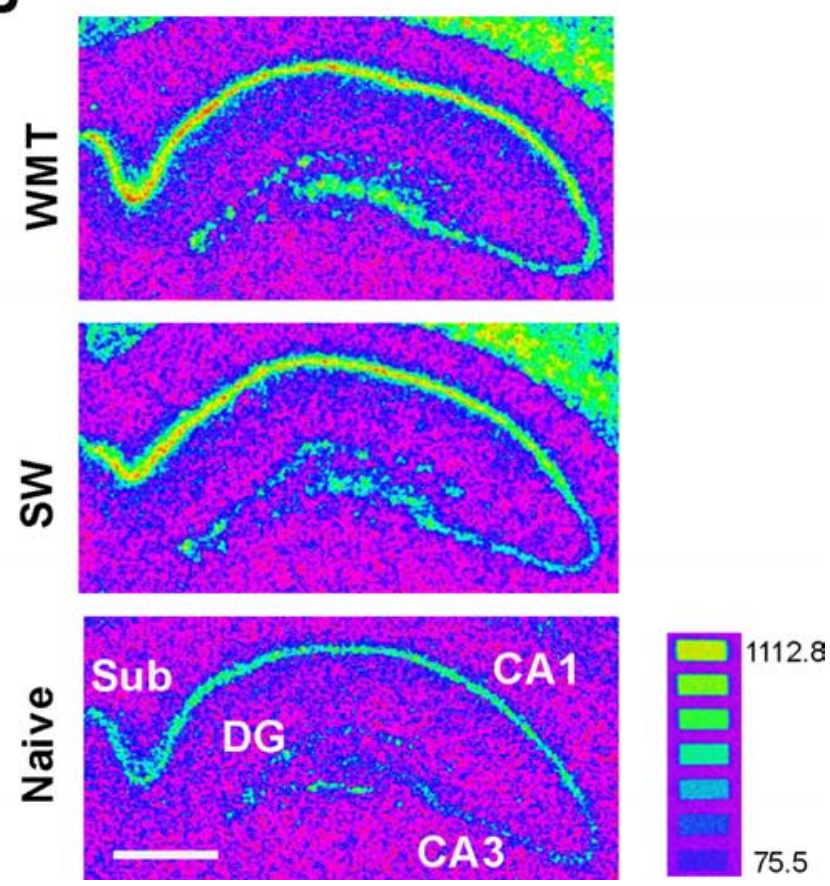

Figure 4. The dorsal hippocampus Arc mRNA upregulation by spatial memory recall at $24 \mathrm{~h}$ and 1 month retention intervals. $\boldsymbol{A}$, Spectrum images of autoradiograms show the elevated Arc mRNA expression in DG (dorsal blade), CA3, CA1, and subiculum after a recent memory test in a WMT rat compared with its SW and naive matched controls. Images of the ${ }^{14} \mathrm{C}$ microscales that were exposed in parallel with the samples illustrate the conversion of mean gray level into nanocuries per gram of tissue equivalents. The mean values in WMT, SW, and naive rats (experimental group 1), respectively, of Arc mRNA signal measured over the entire CA1 $(644.5,415.5$, and $254.3 \mathrm{nCi} / \mathrm{g})$, CA3 $(247.1,197.4$, and $103 \mathrm{nCi} / \mathrm{g})$, subiculum $(843.95,475.24$, and 227.45 $\mathrm{nCi} / \mathrm{g})$, and dorsal blade of DG (199.91, 143.94, and $113.63 \mathrm{nCi} / \mathrm{g})$ are shown. Scale bar, $1 \mathrm{~mm}$. $B$, Autoradiograms show characteristic for long-term memory recall elevated Arc mRNA expression in CA3 and subiculum of a WMT rat compared with its SW and naive controls. The mean values in WMT, SW, and naive rats, respectively (experimental group 10), of Arc mRNA signal measured over CA1 (1154, 1123, and $446.2 \mathrm{nCi} / \mathrm{g})$, CA3 (589.1, 346.7, and $124.7 \mathrm{nCi} / \mathrm{g})$, subiculum $(1339,1142$, and $339.3 \mathrm{nCi} / \mathrm{g})$, and DG $(360.6,321$, and $113.2 \mathrm{nCi} / \mathrm{g})$ are shown. The across the first, second, and third trials, for neither recent nor long-term memory tests (Table 1 ). There was also no difference between the escape latencies for the last day of training and for the last probe tests for both recent and long-term memory. Instead, for 1 month rats, there was a tendency toward performance improvement over repetitive probe tests.

Although the corticosterone level in both WMT and SW rats was elevated compared with the caged controls after recent memory tests and control swimming $\left(F_{(2,9)}=7.86, p<0.02 ; p<0.02\right.$, $p<0.005$, respectively; Fisher's post hoc test; four triads) (Fig. $1 J$ ), there was no difference between the experimental groups in hormone concentration ( $p>0.4$ ), speed of swimming, and distance swum $(p>0.8)$, nor did we find a difference in the stress hormone levels between the WMT and SW rats exposed only to the context of the training room $24 \mathrm{~h}$ after the last training session $\left(F_{(2,9)}=3.52 ; p>0.07\right.$; four triads) (Fig. $\left.1 I\right)$. The performance level of recent memory groups used for mapping and stress studies was not different as assessed by numbers of platform area crossings $(p>0.8)$, dwell times $(p>0.5)$, and distance $(p>0.5)$ in the target quadrant, with latency to the first target slightly longer in the latter set $(p<0.05)$.

\section{Hippocampal circuits that underlie recent and long-term spatial memory activation are distributed throughout multiple septotemporal levels}

Multiple univariate ANOVAs followed by Fisher's post hoc test were applied to determine the presence of the task-specific signal at the level of the entire HC in DG, CA3, CA1, and subiculum (Table 2). After the platform searches based on both recent and long-term memories, we found compelling learning-specific signals in the DG, CA3, and subiculum as a difference in Arc mRNA level between the WMT and SW groups. The specific signal at the level of the entire CA1, however, was detected after recent memory activation but not 1-month-old memory (Table 2).

Visual surveys of scatter plots of Arc mRNA normalized levels against the interaural coordinates indicated that neurons with enhanced Arc mRNA expression could be found at multiple septotemporal levels of DG (Fig. 2A,B), CA3 (Fig. 2C,D), and subiculum (Fig. $2 G, H$ ) but not in CA1 (Fig. 2, compare $E, F$ ) after navigation based on both recent and long-term memory. Although there was always a strong twofold to threefold Arc mRNA upregulation in both WMT and SW rats compared with caged naive controls (Fig. 2), the topography of learning-specific signal had changed over the memory retention period.

\section{The dorsal and ventral $\mathrm{HC}$ in recent and long-term memory} recall: dissociation in $\mathrm{CA} 3$ and $\mathrm{CA} 1$ activation

We focused further on factors that could determine spatial memory representation at the level of the dorsal and ventral $\mathrm{HC}$ because it had been suggested that these regions could have specialized roles in memory function (Moser et al., 1995; Moser and Moser, 1998a; Bannerman et al., 1999, 2004).

Three-way ANOVA indicated significant main effects of all factors such as dorsal and ventral locations $\left(F_{(1,1603)}=7.49 ; p<\right.$ $0.007)$, anatomical subdivision $\left(F_{(3,1603)}=4.17 ; p<0.006\right)$, and memory retention time $\left(F_{(1,1603)}=28.74 ; p<0.0001\right)$ on Arc

\section{$\leftarrow$}

small and inconsistent difference between WMT and SW controls was characteristic for CA1. The DG-specific signal was smaller but consistent. Displayed images represent different in situ hybridization experiments and therefore cannot be compared directly over the memory retention period. 
mRNA navigation-specific expression in the HC (Fig. 3). The F statistics for interaction among dorsal and ventral locations, anatomical subdivision, and memory retention time factors, and for interaction between the dorsal and ventral locations and the anatomical subdivision did not reach the significance level in the threefactor design $\left(F_{(3,1603)}=2.3, p=0.076\right.$; $F_{(3,1603)}=2.54, p=0.055$, respectively); however, an inspection of interaction plots suggested that the effect of the factors (as cited above) on CA1 and subiculum signals was the most similar, whereas the most distinct behavior among the four $\mathrm{HC}$ subdivisions was characteristic of the CA3 signals (Fig. $3 A, B$ ). The DG signal transformation was more reminiscent of CA1 and subiculum signal dynamics.

At $24 \mathrm{~h}$ in memory retention, the navigation-specific Arc mRNA expression was observed in all anatomical subdivisions at the level of both the dorsal and ventral HC (Table 2). We observed, however, a transformation of magnitude of learning-specific signal across the anatomical subdivisions and within the subdivisions along the septotemporal hippocampal axis. In the dorsal $\mathrm{HC}$, the specific signal intensity decreased progressively between the DG and the CA3, the CA1, and the subiculum: CA1 < CA3, CA1 $<$ DG, subiculum $<$ DG $\left(F_{(3,525)}=\right.$ 5.51, $p<0.001 ; p<0.03, p<0.0001, p<$ 0.02 , respectively; Fisher's post hoc test) (Fig. $3 A, B$ ). A different relation between subdivisions was observed in the ventral $\mathrm{HC}$, in which DG, CA1, and subiculum signal magnitudes were similar, and the smallest signal appeared in CA3 neurons, although the ANOVA did not reach the significance level $\left(F_{(3,180)}=5.51 ; p>\right.$ 0.051 ) (Fig. $3 A$ ). The ventral segments of the cortical output subdivisions CA1 and subiculum expressed the most prominent specific signal compared with their dorsal segments $(t=3.55, p<0.0001 ; t=3.29$, $p<0.001$; for CA1 and subiculum, respectively; Student's $t$ test). No such asymmetry was observed in DG $(t=0.9 ; p>0.35)$ and CA3 $(t=-1.59 ; p>0.11)$; therefore, recall of recent spatial memory activated both the dorsal and ventral $\mathrm{HC}$, and the signal was found at each stage of the HC trisynaptic circuitry (Figs. $4 A, 5 A$; representative autoradiograms in the dorsal and ventral $\mathrm{HC}$ are shown). Experiments with the sense Arc riboprobe did not yield specific signal in all groups (data not shown).

A long-term memory test induced task-specific Arc mRNA expression that was significantly different from recent memory despite a behavioral performance
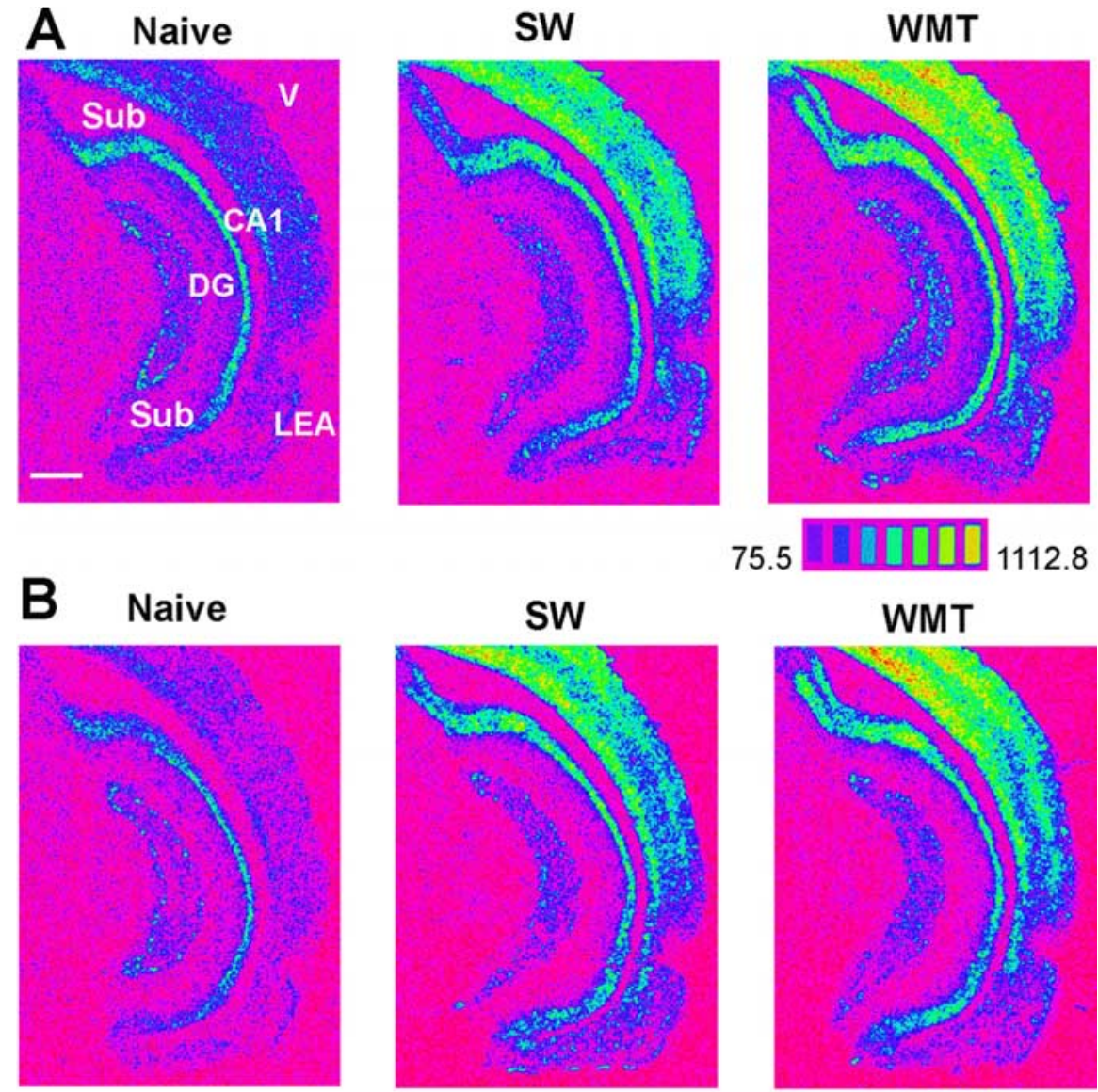

75.5
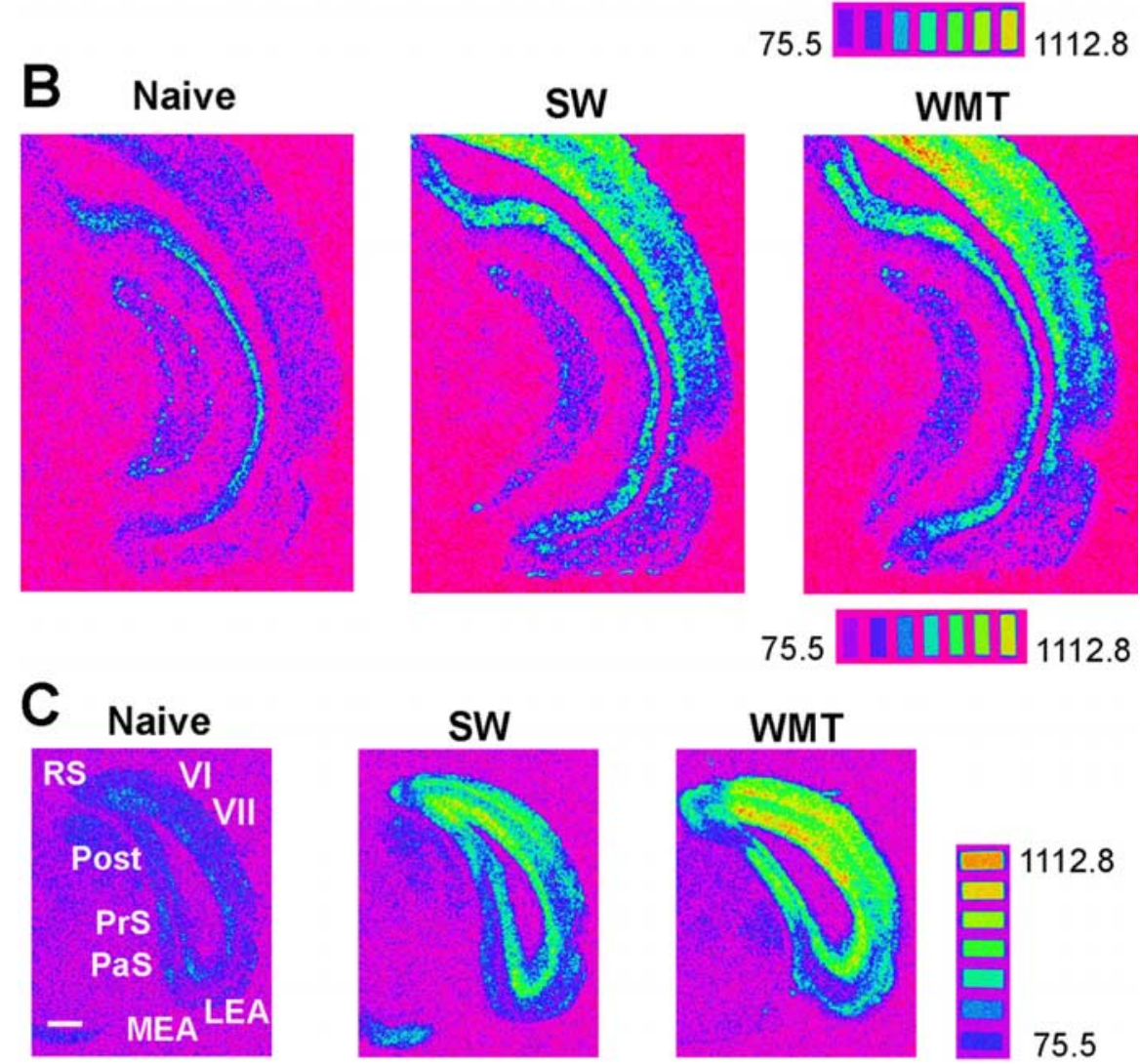

75.5

1112.8

\section{Naive}
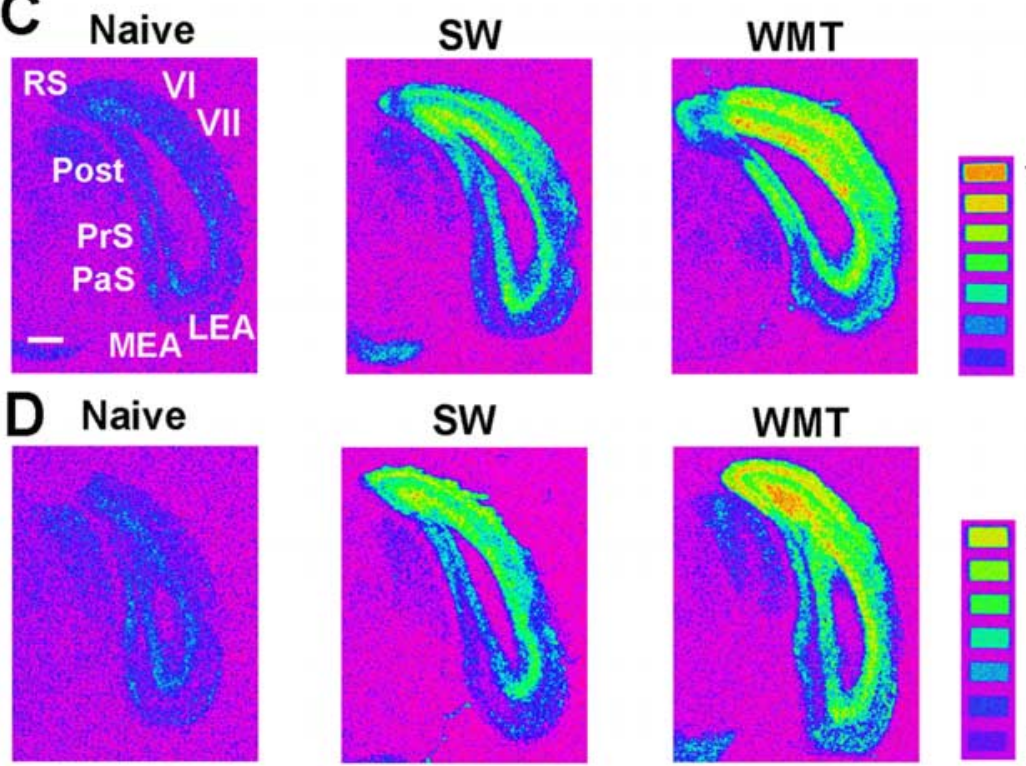

1112.8
SW

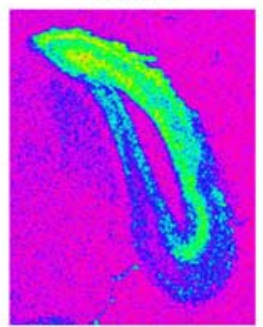

WMT

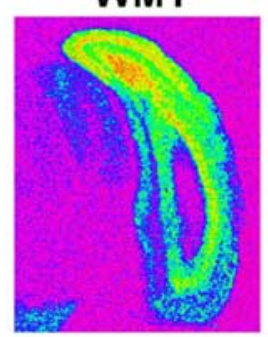

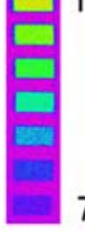

75.5

Figure 5. Arc mRNA upregulation in the ventral hippocampus and entorhinal cortex by spatial memory recall at $24 \mathrm{~h}$ and 1 month retention intervals. $A$, Spectrum images of autoradiograms show characteristically elevated Arc $m R N A$ expression in the DG, CA1, subiculum, and rostral LEA after a recent spatial memory test in a WMT rat compared with SW, and naive controls. Mean values of Arc mRNA signal were measured over the entire regions in WMT, SW, and naive rats, respectively, (experimental group 4) in CA1 (631.3, 394.2, and $313.5 \mathrm{nCi} / \mathrm{g})$, DG (158.6, 78.7, and $115.3 \mathrm{nCi} / \mathrm{g})$, upper subiculum $(445.4,251.7$, and $193.3 \mathrm{nCi} / \mathrm{g})$, lower subiculum (353.6, 205.4, and $131 \mathrm{nCi} / \mathrm{g})$, and rostral LEA (123.4, 91, and $32.3 \mathrm{nCi} / \mathrm{g})$. Scale bar, $1 \mathrm{~mm}$. $\boldsymbol{B}$, Autoradiograms show characteristically elevated Arc mRNA expression in subiculum but not in rostral LEA after the long-term spatial memory test. The Arc mRNA expression in CA1 of the WMT and SW control animals did not differ, and there was a moderate but consistent increase in DG. Mean values of Arc mRNA signal were measured over CA1 (485.1, 488.6, and $297.9 \mathrm{nCi} / \mathrm{g}$; experimental group 10), 
level that had not been affected up to this point. CA1 and CA3 displayed the most profound differences in the dynamics of the specific signal over the memory retention period (Fig. 3B). Although the learning-specific signal disappeared at the level of the dorsal CA1 and ventral CA1, the dorsal CA3 and dorsoventral CA3 still displayed robust learning-specific activity. Navigationspecific signals were observed in DG and subiculum at the level of both the dorsal and ventral HC (Table 2; Fig. $3 A, B$ ); however, Arc mRNA task-specific expression significantly declined in magnitude in the dorsal segments of DG $(t=4.04 ; p<0.0001)$ and CA3 $(t=2.47 ; p<0.02)$, and ventral segments of subiculum $(t=3.92 ; p<0.0001)$ but not in dorsal subiculum $(p>0.31 ; t=$ $-1.01)$, ventral DG $(p>0.28 ; t=-1.09)$, and dorsoventral CA3 $(p>0.9 ; t=0.87)$. In contrast to the recent memory test, no significant differences were observed between subdivisions in the ventral $\mathrm{HC}\left(F_{(3,164)}=1.43 ; p>0.2\right)$ and within all subdivisions between the dorsal and ventral segments as well (CA1: $t=0.38$, $p>0.6$; CA3: $t=-0.65, p>0.5$; DG: $t=1.56, p>0.1$; subiculum: $t=0.17, p>0.8$ ) (Fig. 3 ). See Figures $4 B$ and $5 B$ for representative autoradiograms of the dorsal and ventral HC.

Retrieval of remote memory also activated both the dorsal and ventral $\mathrm{HC}$; however, there was a significant decline in overall magnitude and pattern complexity of learning-specific $\mathrm{HC}$ activity. Over the 1 month retention period, CA3 and the dorsal HC displayed the most persistent specific activity among the subdivisions and at the level of the entire $\mathrm{HC}$, respectively, whereas CA1 and the ventral HC displayed the most dramatic decline in activity. In contrast to recent memory, there was a substantial dissociation in specific activity of anatomically connected CA3 and CA1 subfields in trisynaptic circuitry during remote memory recall at the level of both the dorsal and ventral $\mathrm{HC}$.

More detailed knowledge of the anatomical involvement of the $\mathrm{HC}$ in water-maze memory retrieval and especially its possible time dependency resulting from memory consolidation is not available; however, such evidence is critical to our understanding of intricate mechanisms of memory trace storage and reactivation. We therefore asked whether activity segregation could occur at a smaller scale in the $\mathrm{HC}$ segments.

\section{Memory retention and anatomical segregation of learning- specific Arc mRNA expression in the HC anatomical subdivisions}

Anatomical segregation of information processing within the $\mathrm{HC}$ anatomical subdivisions has been suggested on the basis of lamellar organization of the CA3 to CA1 connection (Andersen et al., 2000) and on recordings of neuronal activity from animals performing the spatial memory task (Hampson et al., 1999). Mapping of clusters of neurons with different task-specific responses revealed alternating and interleaved 200- to 400- and 600- to $800-\mu \mathrm{m}$-thick CA1 and CA3 segments with similar activity patterns. Previously, we have successfully used transverse $400 \mu \mathrm{m}$ dorsal HC slices in studies of CA1 intracellular correlates of recently acquired water-maze memory (Gusev and Alkon, 2001). To maintain the high degree of anatomical resolution for future studies of enduring memory correlates, we now perform mapping of learning-specific Arc mRNA levels to coronal $400 \mu \mathrm{m}$ consecutive $\mathrm{HC}$ segments that may not directly reflect the $\mathrm{HC}$ lamellar organization (Andersen et al., 2000).

The following describes the results of detailed mapping that indicates clustering of activity in the $\mathrm{HC}$ and a differential segment-by-segment dynamic of Arc mRNA expression induced by navigation on the basis of recently or remotely acquired spatial memory of the water maze (Figs. 6, 7; supplemental Tables 1-4, available at www.jneurosci.org as supplemental material); a summary of these results is presented in a diagram in Figure 9.

\section{Dentate gyrus}

After recent memory activation, a navigation-specific signal of similar magnitudes $\left(F_{(6,128)}=0.91 ; p>0.48\right)$ appeared in most of the $400 \mu \mathrm{m}$ coronal HC segments (seven of nine) (see Figs. $6 \mathrm{~A}$, $9 A$; supplemental Table 1, available at www.jneurosci.org as supplemental material). The signal was absent in both $\mathrm{HC}$ poles and occupied only the central segments of the ventral and dorsal HC after both recent and long-term memory activation. After longterm memory tests, however, specific signals were present in fewer and scattered segments (only 3 of 10), which explains the overall signal reduction seen at the level of the dorsal HC (Fig. 3). There was no difference, however, in the specific signal magnitude among segments containing specific signal $\left(F_{(2,58)}=1.38 ; p>\right.$ 0.25 ), and its magnitude was similar to recent memory recall (Fig. $6 A$; supplemental Table 1, available at www.jneurosci.org as supplemental material). We also observed Arc mRNA clusters in DG (Fig. $4 A$ ) that resemble the c-fos mRNA clusters observed after performance on the odor discrimination task (Hess et al., 1995).

\section{CA3}

After recent memory activation, specific signals of different magnitudes $\left(F_{(5,135)}=3.74, p<0.004 ; p<0.05, p<0.05\right.$; GamesHowell post hoc test; the smallest specific signal was found in two of the most dorsal segments) appeared in most of the studied 400 $\mu \mathrm{m}$ coronal HC segments (six of nine) (Fig. $6 B$ ). After long-term memory tests, the specific signal was present in a similar proportion of segments of similar magnitude ( 6 of $10 ; F_{(5,128)}=0.8 ; p>$ $0.5)$, but the signal and its peak were shifted slightly toward the dorsal pole. Although the signal magnitude was increased in a segment at $6.21-6.6 \mathrm{~mm}$, it decreased in three other segments at 5.01-6.2 mm (Fig. 6B; supplemental Table 2, available at www. jneurosci.org as supplemental material). For both recent and long-term memory activation, the most robust signal was found in the dorsal $\mathrm{HC}$ in the group of neighboring segments with less defined signals in the ventral HC (see Fig. 9C).

\section{CA1}

After recent memory activation, a specific signal of similar magnitude appeared in more than half of the studied $400 \mu \mathrm{m}$ coronal segments (four of seven) of the dorsal HC $\left(F_{(3,86)}=0.71 ; p>0.5\right)$ and in two of four segments of the ventral HC $(p>0.05)$ (Fig. $7 A$; supplemental Table 3, available at www.jneurosci.org as supplemental material). These two large segments in the central parts of the dorsal and ventral HC were separated by two segments without evident enhancement of Arc mRNA expression in which the WMT signal was even lower when compared with SW control (at 3.81$4.2 \mathrm{~mm}$ ). The ventral $\mathrm{HC}$ segment between 2.61 and $3.0 \mathrm{~mm}$ had a higher magnitude of specific signal when compared with three of the dorsal $\mathrm{HC}$ segments upper subiculum (539.5, 438.6, and 179.2 nCi/g), lower subiculum (393.6, 321.1, and $152.8 \mathrm{nCi} / \mathrm{g}), \mathrm{DG}(150.5,128$, and 135.5 $\mathrm{nCi} / \mathrm{g})$, and rostral LEA $(130.6,142.4$, and $36.8 \mathrm{nCi} / \mathrm{q})$. C, Elevated Arc mRNA expression in the MEA and caudal LEA after a recent spatial memory test compared with SW and naive controls (LEA: 194.05, 127.7, and $29.5 \mathrm{nCi} / \mathrm{g} ; \mathrm{MEA}: 130.5,118$, and $48.3 \mathrm{nCi} / \mathrm{g}$; experimental group 3). Scale bar, $1 \mathrm{~mm}$. D, Elevated Arc mRNA expression in the MEA and caudal LEA after a remote memory test compared with SW and naive controls (LEA: 475.4, 229, and 63.4 nCi/g; MEA: 264.3, 120, and 62.1 nCi/g; experimental group 7). Note the heightened Arc mRNA levels in the visual cortex, postsubiculum (Post), parasubiculum (PaS), and presubiculum (PrS) after both recent and remote memory activation. VI, Primary visual cortex; VII, secondary visual cortex; RS, retrosplenial cortex. 
$\left(F_{(5,119)}=7.24, p<0.0001 ; p<0.05\right.$, Games-Howell post hoc test) (Fig. 7A). After long-term memory tests, however, the specific signal was present in only one of eight dorsal segments and was not found among four ventral segments. This explains the complete decline seen in CA1 signal at the level of the dorsal and ventral HC (Fig. 3; supplemental Table 3, available at www.jneurosci.org as supplemental material) (Student's $t$ test comparison). The only dorsal segment with the signal at $6.21-6.6 \mathrm{~mm}$ was also shifted to the dorsal pole in parallel with the peak of long-term signal in CA3, and its magnitude was higher when compared with a recent memory signal in the same segment (Fig. 7A; supplemental Table 3 , available at www.jneurosci.org as supplemental material). There was another segment at 3.81-4.2 $\mathrm{mm}$ in the ventral (but not dorsal) part of the $\mathrm{HC}$ with similar changes; the signal in WMT rats was lower compared with SW after recent but not after long-term memory activation (Fig. 7A). In contrast, in the segment at 5.01-5.4 mm, a navigation-specific signal had become even lower than the signal in the SW control at 1 month in memory retention. Thus, we found opposite dynamics of learningspecific activity in different CA1 segments over 1 month of memory consolidation. Moreover, there was a significant dissociation in the robust activity representing a long-term memory task in CA3 and CA1. In the latter, specific activity was limited almost entirely to recent memory retrieval.

\section{Subiculum}

After recent memory activation, specific signals of almost different magnitudes appeared in three of six studied $400 \mu \mathrm{m}$ coronal segments of the dorsal HC and in two of three segments of the ventral HC $\left(F_{(4,95)}=\right.$ $2.34 ; p>0.06$ ) (see Figs. $7 B, 9 D$; supplemental Table 4, available at www. jneurosci.org as supplemental material). These three HC areas were separated by one to two segments without evident enhancement of Arc mRNA expression. The ventral subiculum area displaying specific signal occupied the same border regions as the ventral CA1 area, and there was no signal at the ventral pole. After long-term memory tests, the specific signal of similar magnitude was present in three of six dorsal segments, and it was found among two of four ventral segments with the same location as after recent memory test $\left(F_{(4,79)}=0.84 ; p>0.5\right)$; however, the signal magnitudes were lower only in the ventral segments but not in the dorsal segments when compared with recent memory (supplemental Table 4, available at www.jneurosci.org as supplemental material).

Some segments displayed specific signal only during recent (5.41-5.8) or remote (4.21-4.6) memory recall, whereas othmo, Month; hr, hour.
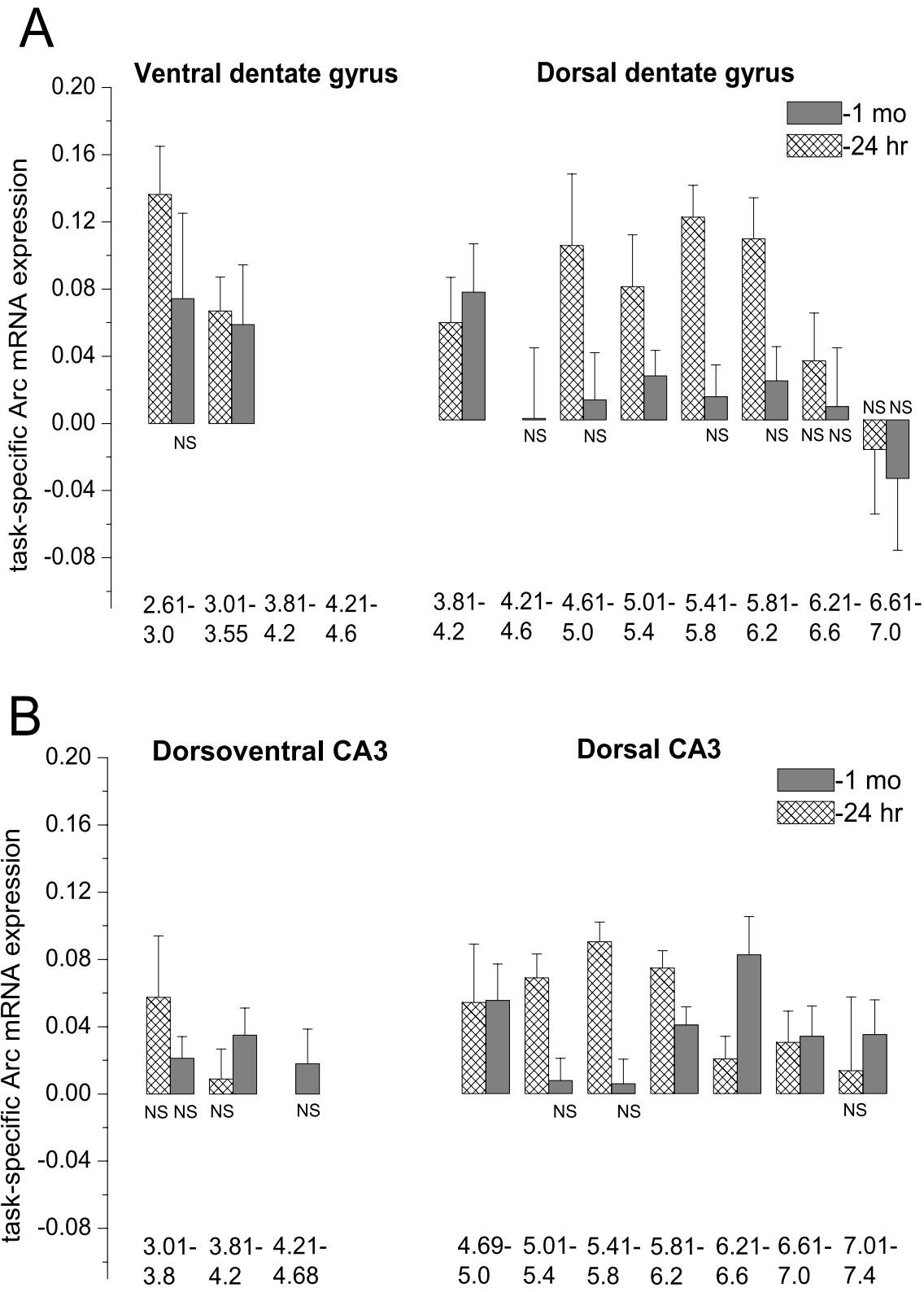

distance from interaural line, $\mathrm{mm}$

Figure 6. Time-dependent topography of $D G$ and $C A 3$ circuits activated during navigation in the water maze on the basis of recent and remote memories. $A$, During a 1 month retention period, the signal magnitude decreased drastically in the two DG segments (spanning $>5.41-6.2 \mathrm{~mm}$ ) and had a similar tendency in three other segments. It was stable in scattered dHC and vHC segments (3.81-4.2 and 3.01-3.55, respectively). $\boldsymbol{B}$, In contrast to DG, the similar amount of CA3 segments displayed specific activity during both recent and remote memory recall; however, the signal and its peak have shifted toward the dorsal pole (compare the dynamic of activity in sectors with borders $5.01-5.8$ and $6.21-7.4 \mathrm{~mm}$, respectively). The numbers indicate the coordinates of the borders of the segments for anatomically matched coronal brain sections from WMT, SW, and naive groups. NS indicates the segment that did not have a statistically significant learning-specific signal (see supplemental Tables 1 and 2, available at www.jneurosci.org as supplemental material for statistical data). The segments with fewer than four data points were not included in the analysis and are not presented. Error bars represent segment SEM of WMT and SW differences. ers did not possess the signal under both conditions (4.01-5.4 and 3.81-4.2, both dorsal and ventral). This explains the overall signal decrease seen at the level of the ventral HC only (Fig. 3 ) and indicates dissociation in specific activity of anatomically connected CA1 and subiculum in a long-term spatial memory task. Note that the specific signal in both CA1 and subiculum was consistently absent at the dorsal and ventral 

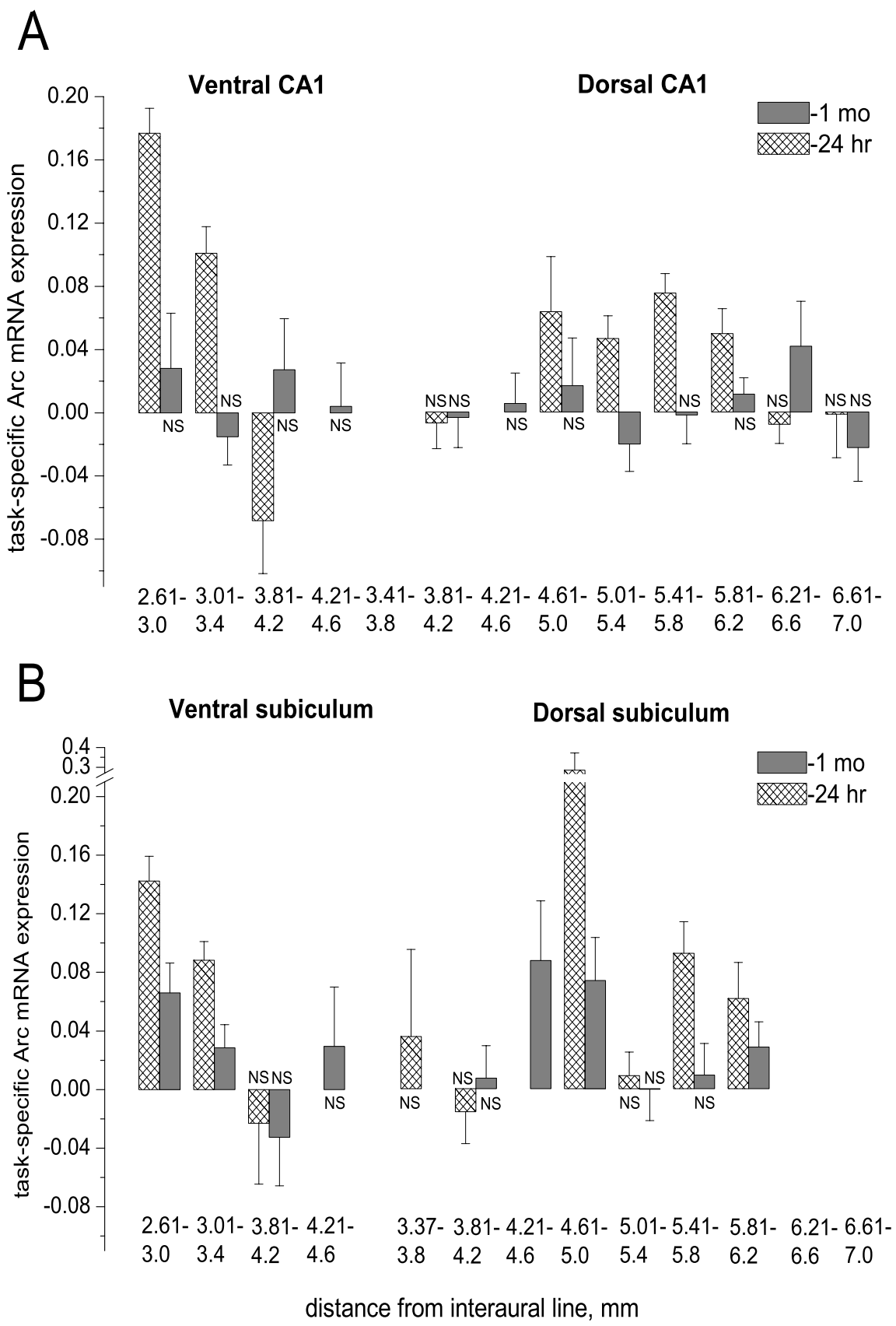

Figure 7. Time-dependent topography of the CA1 and subiculum circuits underlying navigation in water maze on the basis of recent and remote memories. $A$, Over a 1 month retention period, the specific signal disappeared in all dorsal and ventral CA1 segments except the one dorsal segment with coordinates 6.21-6.6, in which it was higher when compared with a recent memory task. $\boldsymbol{B}$, In contrast to $C A 1$, a similar number of subiculum segments displayed specific activity during both recent and remote memory recall. Although the signal magnitude did not change in the dorsal segments (5.81-6.2 and 4.61-5.0), it was drastically reduced in the ventral segments (3.01-3.4 and 2.61-3). mo, Month; hr, hour.

poles of the HC (ventral pole at 3.81-4.2; dorsal pole at 6.616.6) and at the border of the $\mathrm{dHC}$ and the vHC (3.81-4.2) (Fig. $7)$. Thus, there was evidence of clustering of activations, and the cluster patterns in the $\mathrm{HC}$ changed over time.

Lateral and medial areas of the entorhinal cortex are activated by both recent and long-term memory tasks

We measured total Arc mRNA expression across the superficial and deep entorhinal cortex layers. Learning-specific Arc mRNA expression was observed at multiple levels of the medial entorhinal area (MEA) after both recent and long-term memory tests
$\left(F_{(2,120)}=218.4, p<0.0001 ; p<0.0001 ;\right.$ $F_{(2,111)}=406.8, p<0.0001 ; p<0.0001$, Fisher's post hoc test; WMT compared with SW control, respectively) (Figs. 8B, $D, 9 E$ ) (representative autoradiograms are shown in Figure $5 B-D$ ). There was a different dynamic in the lateral entorhinal area (LEA) in which signal related to recent memory could be found in both the rostral ( $\sim 3.5-6$ $\mathrm{mm}$ from the interaural line) and caudal (between 1 and $3.5 \mathrm{~mm})$ LEA $\left(F_{(2,243)}=\right.$ 750.7, $p<0.0001 ; p<0.0001$; Fisher's test; WMT compared with SW control), but after navigation based on long-term memory, it could be found only in the caudal LEA $\left(F_{(2,90)}=462.5, p<0.0001 ; p<\right.$ 0.0001 ) (Figs. $8 A, 9 E$ ) but not in the rostral LEA $\left(F_{(2,213)}=910, p<0.0001 ; p>0.28\right)$ (Fig. $8 C$ ) (representative autoradiograms are shown in Fig. 5B-D). The relative magnitude of the specific signal did not change in the MEA and the caudal LEA over 1 month memory retention $(p>0.2$ and $p>0.01$, respectively; Student's $t$ test).

Thus, we observed distributed ensembles of the entorhinal neurons that displayed Arc mRNA specifically induced by navigation on the basis of recent and remote spatial memories. The data also suggest that entorhinal cortex activation occurs at similar levels during retrieval of recently and remotely acquired spatial memories.

\section{Discussion}

Anatomically distributed throughout the multiple rostrocaudal levels, learningspecific activity was found in subdivisions of both the dorsal and ventral $\mathrm{HC}$ with the neuronal activity marker Arc mRNA during both recent and remote spatial memory recall. Overall, however, long-term memory activation induced a task-specific Arc mRNA expression in the $\mathrm{HC}$ that showed a significant decline in magnitude and pattern complexity compared with recent memory, despite a behavioral performance level that had not been affected up to 1 month in memory retention. Over a 1 month retention period, CA3 and the dorsal HC displayed the most persistent specific activity among the subdivisions and at the level of the entire HC, respectively, whereas CA1 and the ventral HC displayed the most dramatic decline in activity. There was a substantial dissociation in specific activity of anatomically connected CA3 and CA1 subfields in trisynaptic circuitry during remote memory recall. For the first time, detailed mapping revealed cluster organization of memory-related activity in the HC. Some segments of the HC displayed task-specific activity in both recent and long-term memory recall, but other segments were active only in one task. In contrast to the HC, however, at 1 month in memory retention, specific signals comparable with 
recent memory magnitude were found in most areas of the entorhinal cortex.

We based our measurements of learning-specific activity on differences in normalized Arc mRNA levels between WMT and SW control rats after three probe tests. We did not observe extinction in the search behavior across the probe tests that would indicate new learning, nor was there any difference in the swimming distance of the WMT and SW rats that would indicate learned helplessness in SW rats. We also found no differences in stress levels as measured by corticosterone concentration after the recent memory probe tests and context exposure; therefore, the difference in Arc mRNA levels in WMT and SW control rats reflected neuronal activity in the $\mathrm{HC}$ that was related primarily to navigation, in line with previous conclusions (Guzowski et al., 1999, 2001). The variance of data may reflect the sparse memory encoding in the HC (Barnes et al., 1990; Jung and McNaughton, 1993) when only some $20 \mu \mathrm{m}$ sections would display a learning-specific signal.

Our conclusion about the distributed nature of memory underlying circuitry visualized with Arc mRNA throughout both the dorsal and ventral HC is consistent with predictions based on the detrimental effects of partial HC lesions on the performance of rats on a previously mastered water-maze task (Moser et al., 1995; Moser and Moser, 1998a; Bannerman et al., 1999, 2004; Steffenach et al., 2002; Broadbent et al., 2004; de $\mathrm{Hoz}$ et al., 2004), animal neuronal recordings (Hampson et al., 1999; Harris et al., 2003), and theoretical studies (Marr, 1971; McClelland et al., 1995; Rolls, 1996; Fuster, 1997). Divergent topography of the HC afferents and massive systems of DG and CA3 associational projections between the transversal HC segments (Amaral and Witter, 1989; Ishizuka et al., 1990; Li et al., 1994; Burwell and Amaral, 1998; Dolorfo and Amaral, 1998; Burwell, 2000) may underlie two main clusters of learning-specific activity localized in the central parts of the dorsal and ventral $\mathrm{HC}$; however, rostrocaudal differences in pattern and magnitude of Arc mRNA expression, place cell parameters (Jung et al., 1994; Poucet et al., 1994), and synaptic plasticity (Papatheodoropoulos and Kostopoulos, 2000) may underlie differences in mechanisms of the dorsal and ventral HC in spatial memory recall. Persistent activation of the dorsal but not ventral $\mathrm{HC}$ during both recent and remote memory tasks supports the hypothesis that the dorsal $\mathrm{HC}$ is more involved in spatial memory than the ventral $\mathrm{HC}$ (Moser et al., 1995; Moser and Moser, 1998b; Bannerman et al., 1999, 2004). Anatomical segregation of a learning-specific signal in CA1, DG, and subiculum that is characteristic for remote memory retrieval has been described here for the first time and does not have a straightforward basis in the HC anatomical structure; however, will such restricted activation persist over memory retention beyond 1 month?

Different theories of declarative memory agree that circuitry organization underlying memory is time dependent, but there is disagreement about its time scale and the ultimate independence

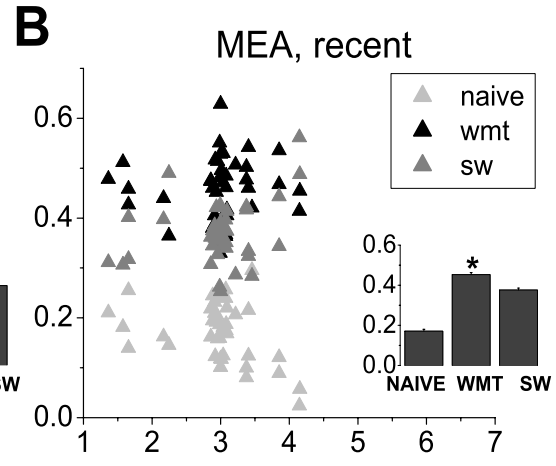

D

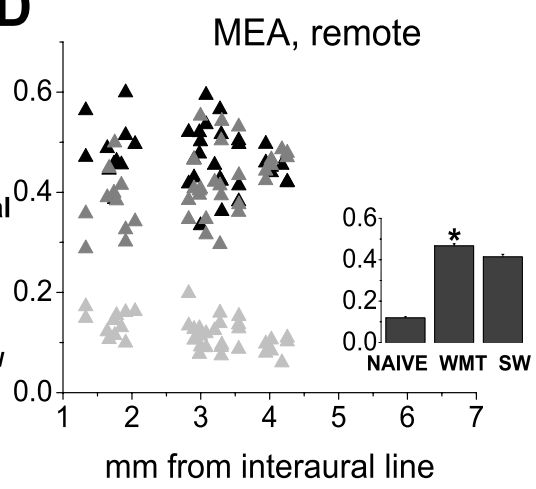

LEA, remote
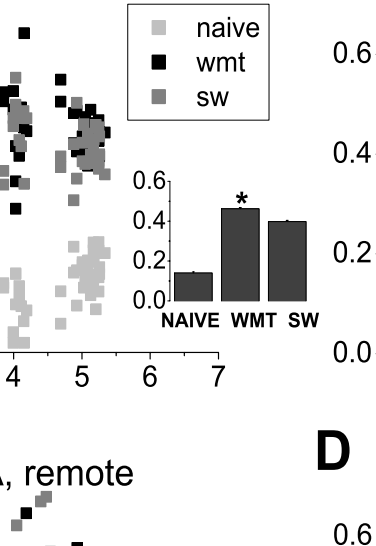

MEA, remote learning-specific Arc mRNA was found at the multiple rostrocaudal levels of MEA during both recent and remote memory recalls. Insets, Normalized Arc mRNA levels in WMT, SW, and naive groups. Data represent SEM. ${ }^{*} p<0.0001$.

of HC integrity. It is thought that storage and retrieval of relational, temporal, and spatial information depends critically on the HC until a cortical memory trace is developed (Marr, 1971; Teyler and DiScenna, 1986; Squire, 1992; McClelland et al., 1995; Rolls, 1996; Milner et al., 1998; Eichenbaum et al., 1999). These theories predict the decreasing $\mathrm{HC}$ role in the coordinated activation of cortical modules over a period of systems-level memory consolidation. In contrast, the multiple memory trace theory proposes continuing $\mathrm{HC}$ involvement in the storage of episodic memory, whereas only more abstract information representing knowledge about facts is transferred for permanent storage into the neocortex (Nadel and Moscovitch, 1997). It is also hypothesized that consolidation is related to proliferation of the intrahippocampal memory traces; thus, we may expect it to be reflected in the increased $\mathrm{HC}$ activity during remote memory recall. The overall decrease of specific hippocampal activity over a 1 month retention period is more consistent with the prediction of a "standard model" of memory consolidation (Squire, 1992); however, an analysis of Arc mRNA expression in the neocortex is necessary for a more definite conclusion.

Task-specific Arc mRNA expression at 1 month in memory retention most likely reflects the critical role of the hippocampus in a remote memory function and thus is not superfluous to successful performance on this task. Numerous early and recent studies demonstrated that a flat retrograde amnesia was induced by lesions of $\mathrm{dHC}$ and the entire $\mathrm{HC}$ at $0.5-3.5$ months in watermaze memory retention (Bolhuis et al., 1994; Mumby et al., 1999; Riedel et al., 1999; Sutherland et al., 2001; Micheau et al., 2004; Clark et al., 2005; Martin et al., 2005). Persistent and robust specific activity in CA3 is complementary to long-term morpho- 
A

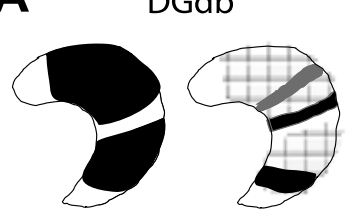

C

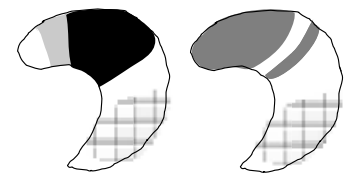

E

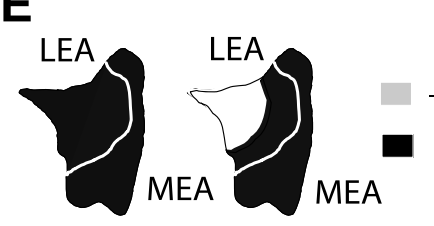

$24 \mathrm{hr}$

$1 \mathrm{mo}$
B

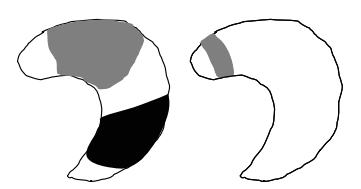

D

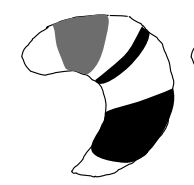

$24 \mathrm{hr}$

$-0.02-0.039$

$-0.08-0.18$

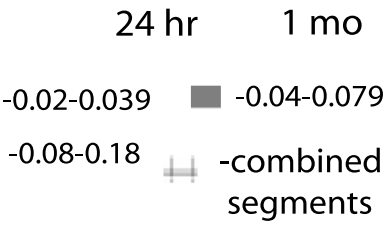

-nonsignificant

Figure 9. Diagrams summarize changes in topography and magnitude of learning-specific Arc mRNA levels in the entorhinal-hippocampal circuitry during recall of recent and 1-monthold water-maze memories. $\boldsymbol{A}$, During 1 month in memory retention, task-specific DG activity, widely and evenly distributed across the multiple $400 \mu \mathrm{m}$ segments, has become limited to a few scattered segments. A weak signal could be identified as learning specific in the rest of the DG segments only if they were combined. $\boldsymbol{B}$, The multiple CA1 segments were specifically activated by recent memory retrieval, whereas only one $\mathrm{dHC}$ segment displayed task-specific activity during a long-term memory task. The ventral CA1 displayed a higher signal compared with the $\mathrm{dHC}$, similar to the ventral subiculum $(\boldsymbol{D})$ during recent recall. $\boldsymbol{C}-\boldsymbol{E}, \mathrm{CA} 3$, subiculum, and the entorhinal cortex displayed the most persistent learning-specific signals after both recent and remote memories recall in contrast to $D G$ and $C A 1$; however, signal representation and magnitude have changed. $C$, In CA3, a weaker signal has been shifted toward the dorsal pole. The CA3 signal did not change in the ventral HC, where it could be identified only in the combined segments. $\boldsymbol{D}$, In the subiculum, the signal occupied mostly the same regions of the $\mathrm{dHC}$ and $\mathrm{vHC}$, but it had a significantly reduced magnitude in the $\mathrm{vHC}$ over a 1 month retention. $\boldsymbol{E}$, Although both MEA and caudal LEA were consistently activated by the navigation task, rostral LEA was specifically activated after performance on a recent memory task. Note that there was no specific activity at the dorsal and ventral HC poles, and there were two sectors of specific activity in the central parts of the $\mathrm{dHC}$ and $\mathrm{vHC}$ separated by segments without it. Statistically significant differences in mean values of signal magnitude in individual segments were coded through their intensity in a gray scale. Data for the diagrams were pooled from supplemental Tables 1-4 (available at www.jneurosci.org as supplemental material) and Figures 3, 6, and 7. For some regions (dorsoventral CA3 and ventral DG), the learning-specific signal could be identified as statistically significant only if the segments were analyzed in combination. DGdb, DG dorsal blade; mo, month; hr, hour.

logical changes found in CA3 stratum oriens (Ramirez-Amaya et al., 2001) and may indicate involvement of the CA3 autoassociative network in recent (Nakazawa et al., 2002, 2003; Meilandt et al., 2004) as well as in long-term memory storage and recall. Mapping data support the idea that DG is not only involved in memory encoding but also participates in memory retrieval (Nanry et al., 1989; Lisman, 1999). The enduring disinhibition of CA1 pyramidal cells found in slices of recently WMT rats may represent transient information storage in CA1 (Gusev and Alkon, 2001). A near-absence of learning-specific activity in CA1 during long-term memory recall indicated by Arc mRNA mapping is consistent with the transient role of CA1 cortical inputs in the water-maze memory consolidation and recall shown by lesion studies (Remondes and Schuman, 2004). Although a single

CA1 segment could still provide a window of communication for the HC output activity that would be necessary for remote memory recall to the subiculum and cortex, most of the CA3 output activity must reach cortical modules indirectly through the lateral and medial septum and through the projections of the latter to subiculum and eventually entorhinal cortex (Risold and Swanson, 1996; Witter and Amaral, 2004). Alternatively, activation of subcortical HC targets could be critical for spatial memory retrieval through $\mathrm{HC}$ involvement in the path integration function (Eichenbaum et al., 1990; Whishaw and Maaswinkel, 1998).

Hypothetically, the overall decreased $\mathrm{HC}$ activity during remote memory recall might reflect the reset of the $\mathrm{HC}$ capacity for fast encoding and storage of new memories (Marr, 1971; McClelland et al., 1995; Rolls, 1996) and is consistent with findings of a temporal HC role in declarative memories such as context fear conditioning (Hall et al., 2001; Frankland et al., 2004) and the radial maze (Bontempi et al., 1999; Maviel et al., 2004). Less favored is the proposed intrahippocampal memory trace proliferation (Nadel and Moscovitch, 1997; Nadel and Bohbot, 2001).

Enhanced Arc mRNA expression could reflect increased firing of neurons that express information retrieved from memory in their goal-directed activity and thus represent memory traces (Wood et al., 2000; Hollup et al., 2001; Fyhn et al., 2002; Nakazawa et al., 2003; Kobayashi et al., 2003). It is thought that HC place cells and head direction cells found in CA1, postsubiculum, anterior dorsal thalamus, and lateral mammillary nuclei are interacting parts of the rodent navigational system (Leutgeb et al., 2000; Calton et al., 2003) that rely on allocentric and idiothetic information processing (Eichenbaum et al., 1990; Whishaw and Maaswinkel, 1998). Arc mRNA and protein localize in the dendrites against the activated synaptic inputs (Steward et al., 1998; Moga et al., 2004). Arc may regulate the cytoskeleton, AMPA and NMDA receptors, and calmodulin-dependent protein kinase II function and thus effectively link learning-induced neuronal activity, structural plasticity, and spine morphogenesis (Guzowski, 2002; Kelly and Deadwyler, 2002; Ying et al., 2002).

In conclusion, during remote spatial memory recall, we observed decreased learning-specific activation of the $\mathrm{HC}$, dissociation in the trisynaptic circuitry for flow of navigation-related activity, and its segregation within small $\mathrm{HC}$ segments in contrast to recent memory; therefore, the mnemonic function of the HC may have changed despite the corticohippocampal interaction maintained at a similar level.

\section{References}

Amaral DG, Witter MP (1989) The three-dimensional organization of the hippocampal formation: a review of anatomical data. Neuroscience 31:571-591.

Andersen P, Soleng AF, Raastad M (2000) The hippocampal lamella hypothesis revisited. Brain Res 886:165-171.

Backman L, Andersson JL, Nyberg L, Winblad B, Nordberg A, Almkvist O (1999) Brain regions associated with episodic retrieval in normal aging and Alzheimer's disease. Neurology 52:1861-1870.

Bannerman DM, Yee BK, Good MA, Heupel MJ, Iversen SD, Rawlins JN (1999) Double dissociation of function within the hippocampus: a comparison of dorsal, ventral, and complete hippocampal cytotoxic lesions. Behav Neurosci 113:1170-1188.

Bannerman DM, Rawlins JN, McHugh SB, Deacon RM, Yee BK, Bast T, Zhang WN, Pothuizen HH, Feldon J (2004) Regional dissociations within the hippocampus: memory and anxiety. Neurosci Biobehav Rev 28:273-283.

Barnes CA, McNaughton BL, Mizumori SJ, Leonard BW, Lin LH (1990) Comparison of spatial and temporal characteristics of neuronal activity in sequential stages of hippocampal processing. Prog Brain Res 83:287-300. Bolhuis JJ, Stewart CA, Forrest EM (1994) Retrograde amnesia and memory 
reactivation in rats with ibotenate lesions to the hippocampus or subiculum. Q J Exp Psychol B 47:129-150.

Bontempi B, Laurent-Demir C, Destrade C, Jaffard R (1999) Timedependent reorganization of brain circuitry underlying long-term memory storage. Nature 400:671-675.

Broadbent NJ, Squire LR, Clark RE (2004) Spatial memory, recognition memory, and the hippocampus. Proc Natl Acad Sci USA 101:14515-14520.

Burwell RD (2000) The parahippocampal region: corticocortical connectivity. Ann NY Acad Sci 911:25-42.

Burwell RD, Amaral DG (1998) Cortical afferents of the perirhinal, postrhinal, and entorhinal cortices of the rat. J Comp Neurol 398:179-205.

Calton JL, Stackman RW, Goodridge JP, Archey WB, Dudchenko PA, Taube JS (2003) Hippocampal place cell instability after lesions of the head direction cell network. J Neurosci 23:9719-9731.

Clark RE, Broadbent NJ, Squire LR (2005) Hippocampus and remote spatial memory in rats. Hippocampus 15:260-272.

de Hoz L, Martin SJ, Morris RG (2004) Forgetting, reminding, and remembering: the retrieval of lost spatial memory. PLoS Biol 2:E225.

Dolorfo CL, Amaral DG (1998) Entorhinal cortex of the rat: topographic organization of the cells of origin of the perforant path projection to the dentate gyrus. J Comp Neurol 398:25-48.

Eichenbaum H, Stewart C, Morris RG (1990) Hippocampal representation in place learning. J Neurosci 10:3531-3542.

Eichenbaum H, Dudchenko P, Wood E, Shapiro M, Tanila H (1999) The hippocampus, memory, and place cells: is it spatial memory or a memory space? Neuron 23:209-226.

Frankland PW, Bontempi B, Talton LE, Kaczmarek L, Silva AJ (2004) The involvement of the anterior cingulate cortex in remote contextual fear memory. Science 304:881-883.

Fuster JM (1997) Network memory. Trends Neurosci 20:451-459.

Fyhn M, Molden S, Hollup S, Moser MB, Moser E (2002) Hippocampal neurons responding to first-time dislocation of a target object. Neuron 35:555-566.

Gallagher M, Rapp PR (1997) The use of animal models to study the effects of aging on cognition. Annu Rev Psychol 48:339-370.

Gusev PA, Alkon DL (2001) Intracellular correlates of spatial memory acquisition in hippocampal slices: long-term disinhibition of CA1 pyramidal cells. J Neurophysiol 86:881-899.

Guzowski JF (2002) Insights into immediate-early gene function in hippocampal memory consolidation using antisense oligonucleotide and fluorescent imaging approaches. Hippocampus 12:86-104.

Guzowski JF, McNaughton BL, Barnes CA, Worley PF (1999) Environment-specific expression of the immediate-early gene Arc in hippocampal neuronal ensembles. Nat Neurosci 2:1120-1124.

Guzowski JF, Lyford GL, Stevenson GD, Houston FP, McGaugh JL, Worley PF, Barnes CA (2000) Inhibition of activity-dependent Arc protein expression in the rat hippocampus impairs the maintenance of long-term potentiation and the consolidation of long-term memory. J Neurosci 20:3993-4001.

Guzowski JF, Setlow B, Wagner EK, McGaugh JL (2001) Experiencedependent gene expression in the rat hippocampus after spatial learning: a comparison of the immediate-early genes Arc, c-fos, and zif268. J Neurosci 21:5089-5098.

Hall J, Thomas KL, Everitt BJ (2001) Cellular imaging of zif268 expression in the hippocampus and amygdala during contextual and cued fear memory retrieval: selective activation of hippocampal CA1 neurons during the recall of contextual memories. J Neurosci 21:2186-2193.

Hampson RE, Simeral JD, Deadwyler SA (1999) Distribution of spatial and nonspatial information in dorsal hippocampus. Nature 402:610-614.

Harris KD, Csicsvari J, Hirase H, Dragoi G, Buzsaki G (2003) Organization of cell assemblies in the hippocampus. Nature 424:552-556.

Hess US, Lynch G, Gall CM (1995) Changes in c-fos mRNA expression in rat brain during odor discrimination learning: differential involvement of hippocampal subfields CA1 and CA3. J Neurosci 15:4786-4795.

Hollup SA, Molden S, Donnett JG, Moser MB, Moser EI (2001) Place fields of rat hippocampal pyramidal cells and spatial learning in the water maze. Eur J Neurosci 13:1197-1208.

Ishizuka N, Weber J, Amaral DG (1990) Organization of intrahippocampal projections originating from CA3 pyramidal cells in the rat. J Comp Neurol 295:580-623.

Jung MW, McNaughton BL (1993) Spatial selectivity of unit activity in the hippocampal granular layer. Hippocampus 3:165-182.
Jung MW, Wiener SI, McNaughton BL (1994) Comparison of spatial firing characteristics of units in dorsal and ventral hippocampus of the rat. J Neurosci 14:7347-7356.

Kelly MP, Deadwyler SA (2002) Acquisition of a novel behavior induces higher levels of Arc mRNA than does overtrained performance. Neuroscience 110:617-626.

Kobayashi T, Tran AH, Nishijo H, Ono T, Matsumoto G (2003) Contribution of hippocampal place cell activity to learning and formation of goaldirected navigation in rats. Neuroscience 117:1025-1035.

Lee I, Yoganarasimha D, Rao G, Knierim JJ (2004) Comparison of population coherence of place cells in hippocampal subfields CA1 and CA3. Nature 430:456-459.

Leutgeb S, Ragozzino KE, Mizumori SJ (2000) Convergence of head direction and place information in the CA1 region of hippocampus. Neuroscience 100:11-19.

Leutgeb S, Leutgeb JK, Treves A, Moser MB, Moser EI (2004) Distinct ensemble codes in hippocampal areas CA3 and CA1. Science 305:1295-1298.

Li XG, Somogyi P, Ylinen A, Buzsaki G (1994) The hippocampal CA3 network: an in vivo intracellular labeling study. J Comp Neurol 339:181-208.

Link W, Konietzko U, Kauselmann G, Krug M, Schwanke B, Frey U, Kuhl D (1995) Somatodendritic expression of an immediate early gene is regulated by synaptic activity. Proc Natl Acad Sci USA 92:5734-5738.

Lisman JE (1999) Relating hippocampal circuitry to function: recall of memory sequences by reciprocal dentate-CA3 interactions. Neuron 22:233-242.

Lyford GL, Yamagata K, Kaufmann WE, Barnes CA, Sanders LK, Copeland NG, Gilbert DJ, Jenkins NA, Lanahan AA, Worley PF (1995) Arc, a growth factor and activity-regulated gene, encodes a novel cytoskeletonassociated protein that is enriched in neuronal dendrites. Neuron 14:433-445.

Marr D (1971) Simple memory: a theory for archicortex. Philos Trans R Soc Lond B Biol Sci 262:23-81.

Martin SJ, de Hoz L, Morris RG (2005) Retrograde amnesia: neither partial nor complete hippocampal lesions in rats result in preferential sparing of remote spatial memory, even after reminding. Neuropsychologia 43:609-624.

Maviel T, Durkin TP, Menzaghi F, Bontempi B (2004) Sites of neocortical reorganization critical for remote spatial memory. Science 305:96-99.

McClelland JL, McNaughton BL, O'Reilly RC (1995) Why there are complementary learning systems in the hippocampus and neocortex: insights from the successes and failures of connectionist models of learning and memory. Psychol Rev 102:419-457.

Meilandt WJ, Barea-Rodriguez E, Harvey SA, Martinez Jr JL (2004) Role of hippocampal CA3 $\mu$-opioid receptors in spatial learning and memory. J Neurosci 24:2953-2962.

Micheau J, Riedel G, Roloff EL, Inglis J, Morris RG (2004) Reversible hippocampal inactivation partially dissociates how and where to search in the water maze. Behav Neurosci 118:1022-1032.

Miller JA (1991) The calibration of ${ }^{35} \mathrm{~S}$ or ${ }^{32} \mathrm{P}$ with ${ }^{14} \mathrm{C}$-labeled brain paste or ${ }^{14} \mathrm{C}$-plastic standards for quantitative autoradiography using LKB Ultrofilm or Amersham Hyperfilm. Neurosci Lett 121:211-214.

Milner B, Squire LR, Kandel ER (1998) Cognitive neuroscience and the study of memory. Neuron 20:445-468.

Moga DE, Calhoun ME, Chowdhury A, Worley P, Morrison JH, Shapiro ML (2004) Activity-regulated cytoskeletal-associated protein is localized to recently activated excitatory synapses. Neuroscience 125:7-11.

Morris R (1984) Developments of a water-maze procedure for studying spatial learning in the rat. J Neurosci Methods 11:47-60.

Moser MB, Moser EI (1998a) Distributed encoding and retrieval of spatial memory in the hippocampus. J Neurosci 18:7535-7542.

Moser MB, Moser EI (1998b) Functional differentiation in the hippocampus. Hippocampus 8:608-619.

Moser MB, Moser EI, Forrest E, Andersen P, Morris RG (1995) Spatial learning with a minislab in the dorsal hippocampus. Proc Natl Acad Sci USA 92:9697-9701.

Mumby DG, Astur RS, Weisend MP, Sutherland RJ (1999) Retrograde amnesia and selective damage to the hippocampal formation: memory for places and object discriminations. Behav Brain Res 106:97-107.

Nadel L, Bohbot V (2001) Consolidation of memory. Hippocampus 11:56-60. 
Nadel L, Moscovitch M (1997) Memory consolidation, retrograde amnesia and the hippocampal complex. Curr Opin Neurobiol 7:217-227.

Nakazawa K, Quirk MC, Chitwood RA, Watanabe M, Yeckel MF, Sun LD, Kato A, Carr CA, Johnston D, Wilson MA, Tonegawa S (2002) Requirement for hippocampal CA3 NMDA receptors in associative memory recall. Science 297:211-218.

Nakazawa K, Sun LD, Quirk MC, Rondi-Reig L, Wilson MA, Tonegawa S (2003) Hippocampal CA3 NMDA receptors are crucial for memory acquisition of one-time experience. Neuron 38:305-315.

Nanry KP, Mundy WR, Tilson HA (1989) Colchicine-induced alterations of reference memory in rats: role of spatial versus non-spatial task components. Behav Brain Res 35:45-53.

Papatheodoropoulos C, Kostopoulos G (2000) Dorsal-ventral differentiation of short-term synaptic plasticity in rat CA1 hippocampal region. Neurosci Lett 286:57-60.

Paxinos G, Watson C (1998) The rat brain in stereotaxic coordinates. London: Academic.

Pothuizen HH, Zhang WN, Jongen-Relo AL, Feldon J, Yee BK (2004) Dissociation of function between the dorsal and the ventral hippocampus in spatial learning abilities of the rat: a within-subject, within-task comparison of reference and working spatial memory. Eur J Neurosci 19:705-712.

Poucet B, Thinus-Blanc C, Muller RU (1994) Place cells in the ventral hippocampus of rats. NeuroReport 5:2045-2048.

Ramirez-Amaya V, Balderas I, Sandoval J, Escobar ML, Bermudez-Rattoni F (2001) Spatial long-term memory is related to mossy fiber synaptogenesis. J Neurosci 21:7340-7348.

Remondes M, Schuman EM (2004) Role for a cortical input to hippocampal area CA1 in the consolidation of a long-term memory. Nature 431:699-703.

Riedel G, Micheau J, Lam AG, Roloff E, Martin SJ, Bridge H, Hoz L, Poeschel B, McCulloch J, Morris RG (1999) Reversible neural inactivation reveals hippocampal participation in several memory processes. Nat Neurosci 2:898-905.

Risold PY, Swanson LW (1996) Structural evidence for functional domains in the rat hippocampus. Science 272:1484-1486.

Rolls ET (1996) A theory of hippocampal function in memory. Hippocampus 6:601-620.

Schreurs BG, Tomsic D, Gusev PA, Alkon DL (1997) Dendritic excitability microzones and occluded long-term depression after classical conditioning of the rabbit's nictitating membrane response. J Neurophysiol 77:86-92.

Schreurs BG, Gusev PA, Tomsic D, Alkon DL, Shi T (1998) Intracellular correlates of acquisition and long-term memory of classical conditioning in Purkinje cell dendrites in slices of rabbit cerebellar lobule HVI. J Neurosci 18:5498-5507.

Squire LR (1992) Memory and the hippocampus: a synthesis from findings with rats, monkeys, and humans. Psychol Rev 99:195-231.

Steffenach HA, Sloviter RS, Moser EI, Moser MB (2002) Impaired retention of spatial memory after transection of longitudinally oriented axons of hippocampal CA3 pyramidal cells. Proc Natl Acad Sci USA 99:31943198.

Steward O, Wallace CS, Lyford GL, Worley PF (1998) Synaptic activation causes the mRNA for the IEG Arc to localize selectively near activated postsynaptic sites on dendrites. Neuron 21:741-751.

Sutherland RJ, Weisend MP, Mumby D, Astur RS, Hanlon FM, Koerner A, Thomas MJ, Wu Y, Moses SN, Cole C, Hamilton DA, Hoesing JM (2001) Retrograde amnesia after hippocampal damage: recent vs. remote memories in two tasks. Hippocampus 11:27-42.

Swanson LW (2004) Brain maps: structure of the rat brain. Amsterdam: Elsevier.

Teyler TJ, DiScenna P (1986) The hippocampal memory indexing theory. Behav Neurosci 100:147-154.

Tuokko H, Vernon-Wilkinson R, Weir J, Beattie BL (1991) Cued recall and early identification of dementia. J Clin Exp Neuropsychol 13:871-879.

Vazdarjanova A, Guzowski JF (2004) Differences in hippocampal neuronal population responses to modifications of an environmental context: evidence for distinct, yet complementary, functions of CA3 and CA1 ensembles. J Neurosci 24:6489-6496.

Whishaw IQ, Maaswinkel H (1998) Rats with fimbria-fornix lesions are impaired in path integration: a role for the hippocampus in "sense of direction." J Neurosci 18:3050-3058.

Witter MP, Amaral DG (2004) Hippocampal formation. In: The rat nervous system (Paxinos G, ed), pp 635-704. Amsterdam: Elsevier.

Wood ER, Dudchenko PA, Robitsek RJ, Eichenbaum H (2000) Hippocampal neurons encode information about different types of memory episodes occurring in the same location. Neuron 27:623-633.

Ying SW, Futter M, Rosenblum K, Webber MJ, Hunt SP, Bliss TV, Bramham CR (2002) Brain-derived neurotrophic factor induces long-term potentiation in intact adult hippocampus: requirement for ERK activation coupled to CREB and upregulation of Arc synthesis. J Neurosci 22:1532-1540.

Zhang WN, Pothuizen HH, Feldon J, Rawlins JN (2004) Dissociation of function within the hippocampus: effects of dorsal, ventral and complete excitotoxic hippocampal lesions on spatial navigation. Neuroscience 127: $289-300$. 